\title{
Fully inkjet-printed glucose assay fabricated on highly porous pigment coating
}

\author{
Eveliina Jutila $^{1} \cdot$ Risto Koivunen ${ }^{1} \cdot$ Roger Bollström $^{2} \cdot$ Patrick Gane $^{1}$
}

Received: 9 December 2019 / Accepted: 11 April 2020 / Published online: 6 May 2020

(c) The Author(s) 2020

\begin{abstract}
A simple paper-based microfluidic device, fabricated on a highly porous coating consisting of functionalised calcium carbonate (FCC) pigment and a microfibrillated cellulose (MFC) and/or polyvinyl alcohol (PVOH) binder, was developed for glucose detection. Both the hydrophobic patterns, consisting of alkyl ketene dimer (AKD), and the enzyme ink, consisting of glucose oxidase (GOx), horseradish peroxidase (HRP) and an indicator containing 4-aminoantipyrine (4-AAP), and sodium 3,5-dichloro-2-hydroxy-benzenesulphonic acid (DHBS) were inkjet-printed. Multiple coating formulations were tested using two indicators, potassium iodide (KI) and 4-AAP/DHBS, to find the optimal formulation with regard to detection sensitivity and assay stability. Higher binder concentrations increased the enzyme activity, especially in the case of PVOH. Two coatings, containing either solely MFC or both MFC and PVOH were ultimately chosen for the glucose assay experiments. For the assays, a $42 \mathrm{nl}$ volume of buffered enzyme solution, containing a total of $5.04 \mathrm{mU}$ GOx and approximately $1.01 \mathrm{mU}$ HRP, in combination with $4 \mathrm{mM} 4$-AAP and $8 \mathrm{mM}$ DHBS, was printed, and a $1 \mu$ glucose solution, made up over a range of concentrations, was applied onto the samples to evaluate the response. A good linearity was achieved between detection and glucose concentration between 0.1 and $0.6 \mathrm{mM}$ with both coatings. The assays remained stable for four weeks when stored at $-20^{\circ} \mathrm{C}$. The results show that the functional coated substrates offer a viable alternative to cellulose-based substrates for microfluidic applications enabling the use of small reagent and sample volumes.
\end{abstract}

Keywords Microfluidic device $\cdot$ Paper microfluidics $\cdot$ Highly porous coating $\cdot$ Glucose assay

\section{Introduction}

Microfluidic paper-based analytical devices ( $\mu$ PADs) are simple, convenient tools, which are based on capillary-driven flow of fluids on hydrophilic surfaces. The concept was first introduced by George Whiteside's research group at Harvard University in 2007, who exemplified the use of a patterned paper assay in simultaneous detection of glucose and protein in urine (Martinez et al. 2007). Since then, multiple applications, ranging from point of care (POC) medical diagnosis

Eveliina Jutila

eveliina.jutila@aalto.fi

Patrick Gane

patrick.gane@aalto.fi

1 Department of Bioproducts and Biosystems, School of Chemical Engineering, Aalto University, 00076 Aalto, Helsinki, Finland

2 Omya International AG, Baslerstrasse 42, 4665 Oftringen, Switzerland
(Syedmoradi and Gomez 2017) to environmental monitoring (Meredith et al. 2016; Liu and Morales-Narváez 2019) and food safety (Busa et al. 2016; Weng and Neethirajan 2017), have been reported. The devices provide easy-to-use solutions for POC and onsite testing, especially for resource-poor settings and developing countries. Furthermore, they provide a viable option to conventional instrumentation, while still offering sensitivity, reproducibility and low limits of detection (Syedmoradi and Gomez 2017). The miniaturisation of the diagnostic instruments not only provides affordable versions of diagnostic tools with rapid detection, but also enables the use of small sample and reagent volumes further reducing the costs of testing and diagnosis.

In the simplest form, $\mu$ PADs offer a visual colorimetric detection (Santana-Jiménez et al. 2018), though electrochemical (Mettakoonpitak et al. 2016; Manbohi and Ahmadi 2019) and fluorescence-based detection methods (Thom et al. 2014; Jutila et al. 2018) have also been used to enhance detection sensitivity. The colorimetric devices are best suited for POC purposes, because they do not require expensive 
instrumentation or special skills. The visual results can be quantified by comparing with a calibration chart (Chan et al. 2012) or the samples can be imaged, for example, using a smartphone (Chun et al. 2014; Thom et al. 2014; Kong et al. 2019; Jia et al. 2018; Soni and Jha 2017).

Cellulose-based filter paper (Adkins et al. 2017; Gabriel et al. 2016; Määttänen et al. 2011; Soni and Jha 2017; Chun et al. 2014; Dungchai et al. 2010; Mani et al. 2019; Cha et al. 2012; Klasner et al. 2010) and chromatographic paper (Gabriel et al. 2017; Ghaderinezhad et al. 2017; Olkkonen et al. 2010; Lamas-Ardisana et al. 2018; Zhu et al. 2014) are the most commonly used substrates for $\mu$ PADs. Patterned paper offers a great alternative to conventional microfluidic substrates, such as polymers and silicon, because the capillary action enables an automated fluid transport within the millimetre-sized channels without the need of external pumps (Martinez et al. 2007). Furthermore, the high surface area-volume ratio and the capacity for storing active reagents within the fibre network make them suitable platforms for chemical reactions (Cate et al. 2015). Other substrates, such as nitrocellulose (Costa et al. 2014; Lu et al. 2010), nanocellulose (Uddin et al. 2018), copy paper (Adkins et al. 2017; Määttänen et al. 2011; Dungchai et al. 2010; Cinti et al. 2018) and coated paper (Määttänen et al. 2011; Songov and Toivakka 2016) have been used in microfluidic applications in addition to filter and chromatographic paper. However, copy paper and commercial coated papers as such do not offer as fast wicking as the specialised cellulose-based substrates, making them unfavourable for microfluidic applications (Zhong et al. 2012). In the past, paper-based glucose assays have been successfully fabricated on both copy paper and commercial coated paper, although the assays were based on circular reaction arrays instead of lateral flow (Määttänen et al. 2011), thus limiting additional opportunities for subsequent component analysis, including, for example, chromatographic separation or analyte reaction (Koivunen et al. 2019).

The highly porous pigment coatings used in the current work reported here have been designed specifically for microfluidic purposes. In previous work, we have shown that the wicking properties of the coating can be enhanced through binder selection and optimisation of the binder dosage (Jutila et al. 2018, 2019). Furthermore, we have shown that our coatings are biocompatible and that they offer enhanced sensitivity compared to filter paper (Jutila et al. 2019). We have also shown that the properties of the coating can be altered either completely (Jutila et al. 2019) or locally (Koivunen et al. 2017, 2019) with polyelectrolytes, affecting the transfer and separation of positively or negatively charged molecules on the coating, which may be useful for some microfluidic applications.
The hydrophilic substrate can be patterned using multiple different fabrication techniques including photolithography (Martinez et al. 2007, 2008; Klasner et al. 2010), flexography (Olkkonen et al. 2010), wax printing (Gabrial et al. 2017; Lu et al. 2010), cutting (Zhu et al. 2014) stamping (Santana-Jiménez et al. 2018; Gabriel et al. 2016) and inkjet printing (Abe et al. 2008, 2010). Each of these methods have their advantages and disadvantages relating to ease of fabrication and resolution. Inkjet printing is a suitable technique for our coated substrates because it is a non-impact printing method, it enables deposition of picoliter volumes and, thus, provides good printing resolution, and because it can be used both to pattern the substrate and to print biomolecules, such as enzymes, and, therefore, the whole assay can be fabricated using a single method.

We have chosen a simple glucose assay to demonstrate the feasibility of our coated substrates for microfluidic assays because of the vast amount of reference literature available. During the reaction, glucose transforms catalytically into gluconic acid and hydrogen peroxide $\left(\mathrm{H}_{2} \mathrm{O}_{2}\right)$ in the presence of glucose oxidase (GOx). The peroxidase then oxidises the indicator, resulting in a visible colour change. The colour intensity is proportional to the glucose concentration in the sample, and, thus, a calibration curve can be constructed to determine the glucose concentration of a sample. The physiologically relevant glucose concentration depends greatly on the biological fluid used in testing. According to the World Health Organisation (2019), fasting plasma glucose levels above $7 \mathrm{mM}$ are considered a sign of diabetes. Urine glucose levels may provide an early screening method for diabetes (Yin et al. 2018). The normal glucose concentration in urine is less than $0.6 \mathrm{mM}$, values higher than this are an indicator of glycosuria, usually caused by diabetes (HUSLAB 2019). Researchers have also shown that salivary glucose may be used as a non-invasive method for screening and diagnosing diabetes (Abikshyeet et al. 2012; Agrawal et al. 2013; Tiongco et al. 2018). However, the glucose concentrations in saliva are much lower than in blood. For example, Abikshyeet et al. (2012) found that the mean values for the control group and patient group in salivary samples were $0.07 \mathrm{mM}$ and $0.23 \mathrm{mM}$, respectively. Perhaps, the lowest glucose concentrations have been detected from tear samples, though the concentration depends highly on the tear collection method (Baca et al. 2007).

Potassium iodide (KI) was the first indicator used in a glucose $\mu$ PAD (Martinez et al. 2007). However, other indicators, such as 4-AAP/DHBS (Gabriel et al. 2016), have also been used because they enable detection of smaller glucose concentrations. Furthermore, multiple stabilisers, such as trehalose (Martinez et al. 2007; Gabriel et al. 2016), polyvinyl alcohol (Olkkonen et al. 2010; Soni and Jha 2015), gelatin (Cha et al. 2012; Zhu et al. 2014; Liu et al. 2019) 
and dithiothreito (DTT) (Soni and Jha 2017), have been used to ensure long-term stability of the assays. The glucose enzymes have been often spotted onto a substrate (Martinez et al. 2007; Santana-Jiménez et al. 2018; Dungchai et al. 2010; Klasner et al. 2010; Gabriel et al. 2017; Olkkonen et al. 2010; de Freitas et al. 2018) though other deposition methods, such as screen printing (Määttänen et al. 2011; Lamas-Ardisana et al. 2018) and inkjet printing (Abe et al. 2010; Wilson et al. 2015) take the $\mu \mathrm{PAD}$ a step closer to mass production.

In this work, our aim is to show the feasibility of using coated platforms to fabricate microfluidic assays, highlighting the potential for thin-coated substrates. We demonstrate that coatings comprising highly porous pigment particles can be utilised as optimisable microfluidics platforms, exemplified in the form of a glucose assay, using an inkjet printer both to pattern the coating with hydrophobic ink and to deposit both the enzymes and detection reagents, with the advantages of good linear sensitivity, while utilising smaller enzyme and glucose sample volumes than previously reported.

\section{Materials and methods}

The assay construct consists of formulated alkyl ketene dimer (AKD) ink as hydrophobising agent for microfluidic channel boundaries, and reagent components consisting of GOx, HRP and a 4-AAP/DHBS indicator. The assay fabrication and analysis workflow is presented in Fig. 1.

\subsection{Functional porous pigment coatings}

A highly porous form of functionalised calcium carbonate (FCC) pigment, provided by Omya International AG, was used as a coating pigment (Fig. 2). The pigment has a high specific surface area $\left(110 \mathrm{~m}^{2} \mathrm{~g}^{-1}\right)$ due to its fine porous intraparticle structure with particles consisting of a calcium carbonate $\left(\mathrm{CaCO}_{3}\right)$ core $(15 \mathrm{w} / \mathrm{w} \%)$ and octacalcium phosphate [hydrolysable to hydroxyapatite $\left.\left(\mathrm{Ca}_{5}(\mathrm{OH})\left(\mathrm{PO}_{4}\right)_{3}\right)\right](85$ w/w\%) outer shell.

Three different binders, a commercial micro-fibrillated cellulose (MFC A), Arbocel MF-40-7 (J.Rettenmaier and Söhne GmbH + Co KG, Rosenberg, Germany), a mechanically produced micro-nanofibrillated cellulose (MFC B) (Schenker et al. 2016, 2017) (Omya International AG, Oftringen, Switzerland), and polyvinyl alcohol (PVOH), BF05 (Omya International AG, Oftringen, Switzerland), were used as binders. The PVOH has a degree of hydrolysis of 98.5-99.2 mol\%, and a molecular weight of 22,000-27,000 $\mathrm{gmol}^{-1}$ (Limpan et al. 2012). Several coating formulations (Table 1) were prepared utilising a magnetic stirrer to determine the optimum formulation for the glucose assays. The coating formulations were optimised to maximise the pigment solids content [quoted as parts by weight in respect to 100 parts by weight of FCC (pph)].

The coating slurries were applied onto an impermeable SUPERYUPO ${ }^{\circledR}$ polypropylene (PP) film (Yupo Corporation, Tokyo, Japan), having a thickness of $80 \mu \mathrm{m}$ and basis weight of $62 \mathrm{gm}^{-2}$, using a K202 Control Coater (RK PrintCoat Instruments Ltd., Litlington, UK). A speed setting of $6 \mathrm{~m} \mathrm{~min}^{-1}$ drawing selected wire-wound rods along the surface, applying a wet film onto the substrate adjustable over a thickness range of $60-300 \mu \mathrm{m}$, was used. Coated samples were dried overnight at room temperature.

\subsection{Pigment and coating characterisation}

The specific surface area of the FCC pigments was measured using the nitrogen adsorption BET method (ISO 9277). The relative pigment mineral content constituting the FCC was determined by X-ray diffraction (XRD) analysis. Scanning electron microscope (SEM) images were obtained with a Sigma VP field emission scanning microscope (Carl Zeiss AG, Oberkocken, Germany).

The solids content of the coating slurries was determined using an oven-drying method, in which the samples were dried at $105{ }^{\circ} \mathrm{C}$ for $24 \mathrm{~h}$, and the weight loss was used to calculate the solids content. Viscosity of the coating slurries was measured with a Brookfield DV-II + viscometer (Brookfield Engineering Laboratories, Inc., Massachusetts, USA) using spindles \#2 and \#3 at $100 \mathrm{~min}^{-1}$ (rpm). $\mathrm{pH}$ was recorded using a Mettler Toledo (Mettler-Toledo International Inc., Columbus, Ohio, USA) SevenEasy pH meter. Coat weight $\left(\mathrm{gm}^{-2}\right)$ was calculated by measuring the weight of $5 \times 5 \mathrm{~cm}^{2}$ pieces of coated PP film, using a Mettler AE260 analytical balance (Mettler-Toledo International Inc., Columbus, Ohio, USA), deducting the weight of uncoated PP film piece from that of the coated piece and dividing by the coated area (sampling number, $n=9$ ). Coating thickness was measured with an SE250D micrometer (Lorenzen and Wettre, Kista, Sweden), having a measurement pressure of $100 \mathrm{kPa}$ and a 2-cm measurement diameter spindle on three spots in each sample. The thickness of the PP film $(80 \mu \mathrm{m})$ was deducted from the thickness of the coated sample $(n=10)$.

\subsection{Cellulose-based reference substrate}

An uncoated cellulose-based substrate, consisting of pure cellulose produced from high-quality cotton linters, Whatman $1 \mathrm{Chr}$ chromatography paper (Whatman CHR1), was used as reference substrate. Whatman CHR1 has a basis weight of $88 \mathrm{gm}^{-2}$ and a thickness of $180 \mu \mathrm{m}$. The average thickness of the cellulose fibres is $15 \pm 1 \mu \mathrm{m}$ (Evans et al. 2014). 


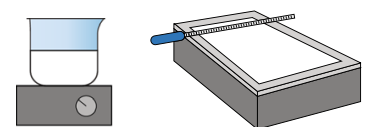

Preparation of the coating and rod coating

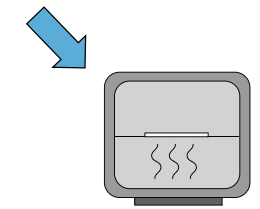

Heat-treatment at $105^{\circ} \mathrm{C}$ to trigger shrinkage of the sheet

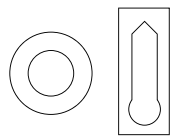

Designing test patterns

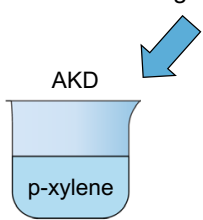

Preparation of hydrophobising ink

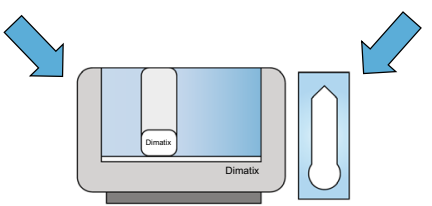

Inkjet printing of hydrophobic patterns

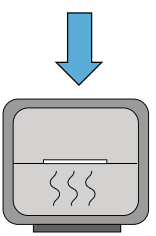

Heat-treatment at $105^{\circ} \mathrm{C}$ to promote reaction

HRP GOx between AKD and the hydroxy groups of the coating

$\mathrm{KI} / 4-\mathrm{AAP} / \mathrm{DHBS}$

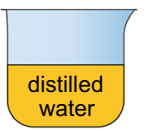

Preparation of enzyme ink

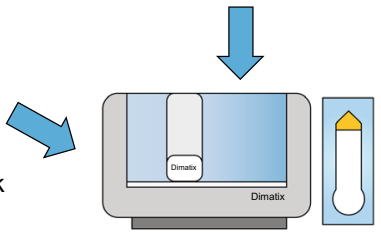

Inkjet printing of enzymes

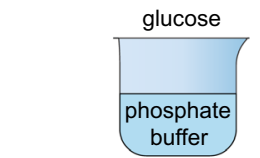

Preparation of glucose solution

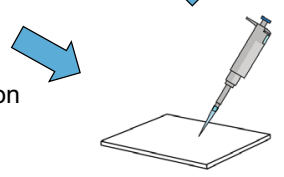

Application of glucose sample

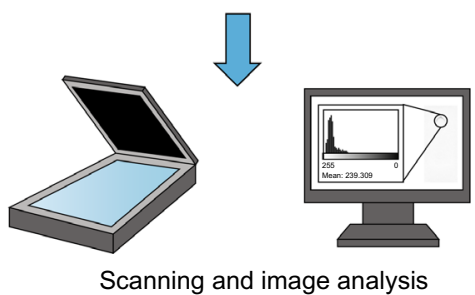

Scanning and image analysis

Fig. 1 Glucose assay fabrication, testing and image analysis process

\subsection{Glucose assay chemicals}

Glucose oxidase/peroxidase reagent (G3660), D- $(+)$ Glucose (G5767), Trehalose (PHR1344), 4-Aminoantinpyrine
(4-APP) (A482), sodium 3,5-dichloro-2-hydroxybenzenesulphonate (DHBS) (D4645) and potassium phosphate dibasic (P3786) were purchased from Sigma Aldrich (Sigma-Aldrich Inc., St. Louis, USA). Potassium 


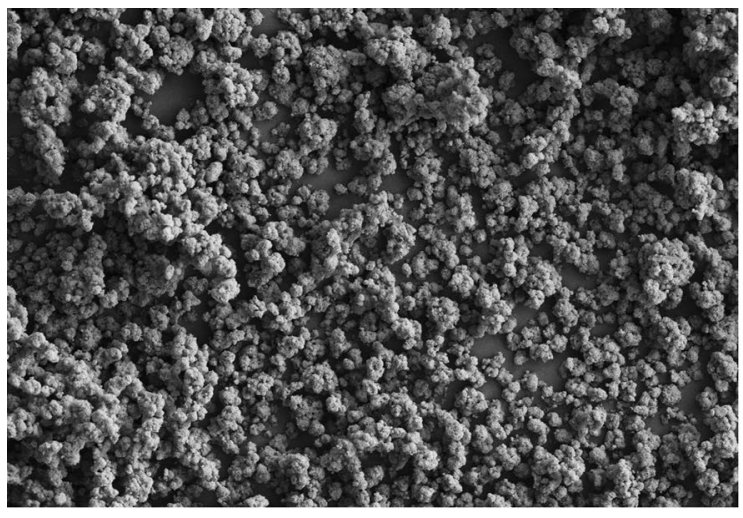

$\longmapsto 20 \mu \mathrm{m}$

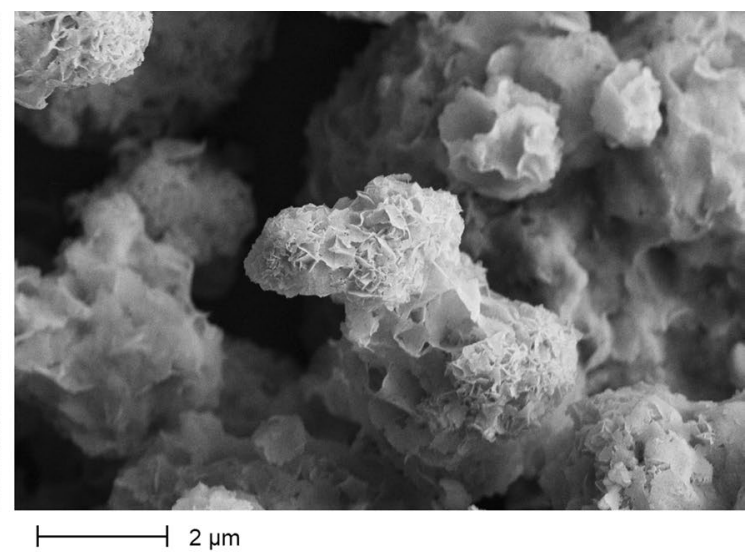

$\longmapsto 2 \mu \mathrm{m}$

Fig. 2 SEM images showing the fine porous structure of the FCC pigment

Table 1 Coating formulations

\begin{tabular}{|c|c|}
\hline Coating & $\begin{array}{l}\text { Solids con- } \\
\text { tent }(\mathrm{w} / \mathrm{w} \%)\end{array}$ \\
\hline $\mathrm{FCC}+5 \mathrm{pph} \mathrm{PVOH}$ & 15.3 \\
\hline $\mathrm{FCC}+10 \mathrm{pph} \mathrm{PVOH}$ & 15.4 \\
\hline $\mathrm{FCC}+10 \mathrm{pph}$ MFC A & 15.6 \\
\hline $\mathrm{FCC}+20 \mathrm{pph} \mathrm{MFC} \mathrm{A}$ & 14.6 \\
\hline $\mathrm{FCC}+10 \mathrm{pph} \mathrm{MFC} \mathrm{B}$ & 6.0 \\
\hline $\mathrm{FCC}+20 \mathrm{pph} \mathrm{MFC} \mathrm{B}$ & 4.0 \\
\hline FCC +10 pph MFC A + 10 pph PVOH & 15.1 \\
\hline $\mathrm{FCC}+20 \mathrm{pph} \mathrm{MFC} \mathrm{A}+10 \mathrm{pph} \mathrm{PVOH}$ & 13.4 \\
\hline $\mathrm{FCC}+10 \mathrm{pph} \mathrm{MFC} \mathrm{B}+10 \mathrm{pph} \mathrm{PVOH}$ & 6.3 \\
\hline $\mathrm{FCC}+20 \mathrm{pph} \mathrm{MFC} \mathrm{B}+10 \mathrm{pph} \mathrm{PVOH}$ & 4.2 \\
\hline
\end{tabular}

dihydrogen phosphate (1048730250) was purchased from Merck KGaA (Darmstadt, Germany) and potassium iodide (KI) (Product code 26843.361) was purchased from VWR (VWR International Bvba, Leuven, Belgium). The enzyme solutions containing GOx and HRP (and buffer salts) and either the KI indicator (brown colour change) or the 4-AAP/DHBS indicator (pink colour change) were prepared in distilled water. The glucose concentration series were prepared in $100-\mathrm{mM}$ phosphate buffer $(\mathrm{pH}=6.0)$.

\subsection{Functional inks and printing}

\subsubsection{Printing of hydrophobic patterning}

Printing was carried out with a DMP-2831 research inkjet printer (Fujifilm Dimatix, Santa Clara, USA) employing DMC-11610 cartridges with 10-pl nominal drop volume. As part of the cartridge filling procedure, inks were filtered with $0.45-\mu \mathrm{m}$ GHP Acrodisc GF syringe filters (Pall Corporation, Port Washington, USA). The printer mounting plate holding the samples was set to a temperature of $30^{\circ} \mathrm{C}$.

Hydrophobising ink consisted of $10 \mathrm{w} / \mathrm{w} \%$ commercial AKD FennoWax 1865 (Kemira, Helsinki, Finland) dissolved in p-xylene. Jetting settings were as described previously by the authors for a similar, though colourant containing, ink in contemporary work (Koivunen et al. 2019). The hydrophobising ink in the present case contains no colourant, resulting in almost invisible printed patterns for minimum background interference in the colorimetric analysis.

Before and after printing with hydrophobising ink, coated sheets were heat-treated for $10 \mathrm{~min}$ in an oven at $105^{\circ} \mathrm{C}$. Initial heat-treatment prior to printing triggers a slight shrinkage of the SuperYupo sheets, irreversible and occurring only once; while, the second heat-treatment after printing is used to promote reactions between AKD and hydroxyl groups
Fig. 3 Schematic of a the ring patterns used in the optimisation experiments, and $\mathbf{b}$ the fully inkjet-printed glucose assay with tip $+1.5 \mathrm{~mm}$ (shown yellow) printed enzyme configuration a

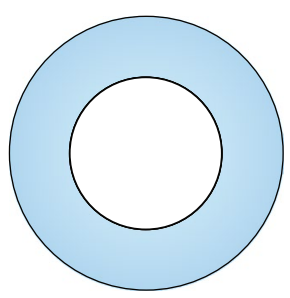

b

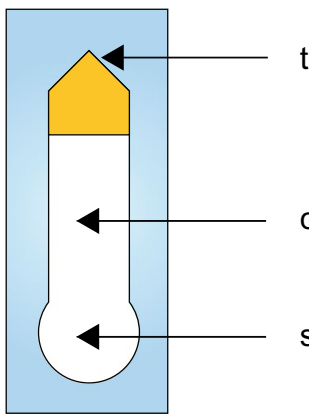

AKD ink

enzyme ink

channel

sample insertion zone

$5 \mathrm{~mm}$ 
Table 2 Enzyme ink contents

\begin{tabular}{ll}
\hline Ingredient & Amount (g) \\
\hline GOx + HRP + buffer salts (1 capsule) & 0.95800 \\
4-AAP & 0.00343 \\
DHBS & 0.00902 \\
DI water & 4.16740 \\
\hline
\end{tabular}

Table 3 Custom waveforms for jetting the enzyme solution

\begin{tabular}{lccc}
\hline Segment & Level $(\%)$ & Slew & Duration $(\mu \mathrm{s})$ \\
\hline Jetting 1 & 100 & 0.30 & 7.040 \\
Jetting 2 & 0 & 0.30 & 20.160 \\
Non-jetting 1 & 20 & 0.30 & 2.632 \\
Non-jetting 2 & 0 & 0.60 & 21.568 \\
\hline
\end{tabular}

amongst the coating components. Printed reference chromatography paper sheets were similarly heat-treated, but only after printing.

Hydrophobic patterns consisted of rings with 9-mm outer and 5-mm inner nominal diameters used in coating optimisation experiments (Fig. 3a), and a final assay pattern design with a short channel with circular sample insertion zone at one end and a triangular reaction zone at the other end (assay dimension $5.5 \times 13.5 \mathrm{~mm}^{2}$ ) (Fig. 3b). The rings were printed at $15-\mu \mathrm{m}$ drop spacing, applying either 1 layer (coating formulations FCC $+10 \mathrm{pph} \mathrm{PVOH}, \mathrm{FCC}+10 \mathrm{pph}$ MFC B +10 pph PVOH, FCC +10 pph MFC A + 10 pph $\mathrm{PVOH}$ and $\mathrm{FCC}+20$ pph MFC A +10 pph $\mathrm{PVOH}$ ) or 2 layers (other coating recipes). The channel patterns were printed on two coating formulations (FCC $+10 \mathrm{pph}$ MFC B and $\mathrm{FCC}+20 \mathrm{pph} \mathrm{MFC} \mathrm{B}+10 \mathrm{pph} \mathrm{PVOH}$ ) at $25-\mu \mathrm{m}$ drop spacing with 2 ink layers applied. On Whatman CHR1, both patterns were printed with 1 layer at $50-\mu \mathrm{m}$ drop spacing.

\subsubsection{Enzymatic patterning}

After hydrophobic patterns were printed and heat-treated, reaction zones were completed by applying enzyme solution, either by manually pipetting $1 \mu \mathrm{l}$ drop of solution at the centre of each ring, or by inkjet depositing variable amount of enzyme solution close to the triangular end of each channel on the fully inkjet-printed glucose assays. The enzyme ink contents used in this study are described in Table 2. The enzyme solution contained 120 units $(\mathrm{U}) \mathrm{cm}^{-3} \mathrm{GOx}$, $24 \mathrm{U} \mathrm{cm}^{-3} \mathrm{HRP}$, together with 4-mM AAP, 8-mM DHBS and buffer salts (sodium and potassium ions). When prepared for inkjet deposition, the contents were allowed to dissolve at room temperature for approximately $3 \mathrm{~h}$ without external agitation.
Enzyme solution printing was conducted with the same equipment as hydrophobic patterning. The solution was jetted with a custom waveform, described in Table 3 , at $5-\mathrm{kHz}$ frequency, 28-V jetting voltage, $30^{\circ} \mathrm{C}$ cartridge temperature and 5-inch $\mathrm{H} 2 \mathrm{O}$ meniscus (12.5 mbar) vacuum, with "spit spit" cleaning cycle run at the beginning of the printing and every 900 s or every 900 print bands, whichever comes first, during the printing.

The printed enzyme patterns consisted of a variable number of drops deposited as a single layer at $25-\mu \mathrm{m}$ drop spacing close to the triangular end of the channel (Fig. 3b). Average dry solids content per inkjet deposited drop of enzyme solution was measured by printing 20 million drops into each of 5 pre-weighed aluminium dishes, drying the dishes overnight in a $105^{\circ} \mathrm{C}$ in an oven and re-weighing the dishes. Average dry solids weight for a $1 \mu \mathrm{l}$ drop of manually pipetted enzyme solution was measured similarly, except that a porous glass fibre disc was placed inside the dish to absorb the liquid and 20 drops were applied per dish.

\subsection{Glucose experiments}

\subsubsection{Optimisation of the coating formulation}

The optimal coating formulation for the glucose assay was determined using the hydrophobic ring patterns (Fig. 3a). In the experiments, $1-\mu l$ enzyme solution containing $120 \mathrm{U} \mathrm{cm}^{-3}$ GOx, $24 \mathrm{~cm}^{-3}$ HRP and either 0.3-M Trehalose and 0.6-mM KI (brown colour change) (Martinez et al. 2007) or 4-mM 4-AAP and 8-mM DHBS (pink colour change) (Gabriel et al. 2016), was applied to the ring patterns manually using a pipette. The enzyme solution was allowed to dry, after which $1 \mu \mathrm{l}$ of glucose containing sample, $1-10 \mathrm{mM}$ in the case of KI indicator and $0.1-1 \mathrm{mM}$ in the case of the 4-AAP/DHBS indicator, was manually applied to the centre of the ring pattern, using a pipette (Finnpipette, Thermo Fisher Scientific, Waltham, Massachusetts, USA). The optimisation experiments were conducted in a climatecontrolled environment $\left(23.5^{\circ} \mathrm{C}\right.$ and $\left.50.2 \% \mathrm{RH}\right)$.

Stability experiments were performed using the KI indicator and a 5-mM glucose concentration. The samples were divided into zipper-type plastic bags, placed in a cardboard box to protect the samples from light and contamination and stored in a fridge at $6{ }^{\circ} \mathrm{C}$. The samples were tested over the course of four weeks.

\subsubsection{Fully inkjet-printed glucose assays}

The fully inkjet-printed glucose assay experiments were performed using two coated substrates, FCC +10 pph MFC B and FCC +20 pph MFC B +10 pph PVOH. The enzymes were inkjet-printed (Fig. 3b), as previously described, and, 
therefore, the experiments were conducted simply by applying 1- $\mu \mathrm{l}$ glucose containing sample $(4 \mu \mathrm{l}$ in the case of the thicker reference paper, Whatman CHR1) with the glucose concentration of $0.1-1.0 \mathrm{mM}$ to the sample insertion zone. The experiments were conducted under normal laboratory conditions without climate control.

Stability experiments for the fully inkjet-printed glucose assays were performed using a glucose concentration of $0.6 \mathrm{mM}$. The samples were stored at room temperature, in the fridge $\left(6^{\circ} \mathrm{C}\right)$ and in a freezer $\left(-20^{\circ} \mathrm{C}\right)$ protected from light and contamination. The samples were tested over the course of four weeks.

\subsection{Scanning and image analysis}

The samples were scanned with an Epson Expression 1680 flatbed scanner (Seiko Epson Corporation, Nagano, Japan) at 1200-dpi resolution to record colour change. The scans of the fully inkjet-printed glucose assays experiments were enhanced using Photoshop CC 2018 (Adobe, San Jose, USA) to improve the image analysis. The overall range of the tonal values of the image was shrank using the contrast slider $(-50)$ and the vibrance slider was applied three times $(+100)$ to increase the intensity of the pink colour to increase the contrast between the different concentration points.

The Image analysis was performed with ImageJ software version 1.52i (National Institutes of Health, Bethesda, USA). The image was first converted into a greyscale 8-bit image, after which the mean grey intensity for each region of interest (ROI) was obtained using the histogram distribution function. A circular ROI with a diameter of 300 pixels was used in the optimisation experiments, in which the ring pattern (Fig. 3a) was utilised. The dyes eluted to the arrowshaped tip (Fig. 3b) in the fully inkjet-printed glucose assay experiments. In these experiments, a circular ROI with a diameter of 125 pixels was used for the FCC +10 pph MFC
B coating and Whatman CHR1 filter paper; while, a rectangular ROI $(100 \times 140$ pixels $)$ was used for the FCC +20 pph MFC B +10 pph PVOH coating, because the pink dye did not elute fully all the way to the tip. The pixel grey level intensity values range between 0 and 255, representing black and white, respectively. To obtain ascending calibration curves of increasing response, the mean grey level intensity values were converted simply by subtracting from 255 , i.e. calibration response $=255$-grey level intensity.

\section{Results and discussion}

\subsection{Coating properties}

Table 4 shows the coating properties for the coatings used in the optimisation experiments. The rods controlling the wet thickness of the coatings were chosen to achieve similar dry thickness for each of the coatings. The addition of the MFC B increases the viscosity of the coating significantly and, thus, a lower coating solids content had to be used to ensure good coating properties (Table 1). To achieve similar dry thickness to those with the other binders, a thicker wet film, therefore, needed to be applied with MFC B containing coatings.

For the fully inkjet-printed glucose assays, the dry thickness of the coatings were reduced to $16 \pm 1 \mu \mathrm{m}$ for $\mathrm{FCC}+10$ pph MFC B and $17 \pm 12 \mu \mathrm{m}$ for FCC +10 pph $\mathrm{PVOH}+20$ ppH MFC B to enable the use of smaller reagent and glucose sample volumes. This way, the assay patterns could be eluted with as low as $0.5-\mu l$ sample volume.

FCC pigments offer high wicking capabilities due to their discretely bimodal pore size distribution (Ridgway et al. 2004, 2006). The coating pore structure consists of intraparticle and interparticle pores, which contribute to high capillarity and permeability, respectively, together acting as a driving force for increased wicking over that of conventional

Table 4 Coating properties, optimisation

\begin{tabular}{|c|c|c|c|c|c|}
\hline Coating & $\mathrm{pH}$ & $\begin{array}{l}\text { Brookfield viscosity @ } \\
100 \mathrm{~min}^{-1} \text { (rpm) (mPas) }\end{array}$ & $\begin{array}{l}\text { Wet thickness } \\
(\mu \mathrm{m})\end{array}$ & $\begin{array}{l}\text { Dry thickness } \\
(\mu \mathrm{m})\end{array}$ & Coat weight $\left(\mathrm{gm}^{-2}\right)$ \\
\hline $\mathrm{FCC}+5 \mathrm{pph} \mathrm{PVOH}$ & 7.45 & 73 & 100 & $59 \pm 3$ & $19.0 \pm 1.3$ \\
\hline $\mathrm{FCC}+10 \mathrm{pph} \mathrm{PVOH}$ & 7.62 & 68 & 100 & $44 \pm 1$ & $14.5 \pm 1.1$ \\
\hline $\mathrm{FCC}+10 \mathrm{pph}$ MFC A & 7.61 & 180 & 100 & $58 \pm 4$ & $16.4 \pm 1.3$ \\
\hline $\mathrm{FCC}+20 \mathrm{pph} \mathrm{MFC} \mathrm{A}$ & 7.67 & 179 & 100 & $52 \pm 1$ & $16.1 \pm 1.2$ \\
\hline $\mathrm{FCC}+10 \mathrm{pph} \mathrm{MFC} \mathrm{B}$ & 7.67 & 502 & 150 & $47 \pm 3$ & $11.7 \pm 0.6$ \\
\hline $\mathrm{FCC}+20 \mathrm{pph} \mathrm{MFC} \mathrm{B}$ & 7.76 & 426 & 300 & $56 \pm 3$ & $13.4 \pm 1.4$ \\
\hline $\mathrm{FCC}+10 \mathrm{pph} \mathrm{PVOH}+10 \mathrm{pph} \mathrm{MFC}$ A & 7.71 & 139 & 100 & $58 \pm 6$ & $16.3 \pm 2.7$ \\
\hline $\mathrm{FCC}+10 \mathrm{pph} \mathrm{PVOH}+20 \mathrm{pph} \mathrm{MFC}$ A & 7.76 & 264 & 100 & $56 \pm 7$ & $18.6 \pm 1.2$ \\
\hline $\mathrm{FCC}+10 \mathrm{pph} \mathrm{PVOH}+10 \mathrm{pph} \mathrm{MFC} B$ & 7.77 & 357 & 200 & $64 \pm 2$ & $16.1 \pm 0.6$ \\
\hline $\mathrm{FCC}+10 \mathrm{pph} \mathrm{PVOH}+20 \mathrm{pph} \mathrm{MFC} \mathrm{B}$ & 7.86 & 347 & 300 & $59 \pm 3$ & $14.6 \pm 0.8$ \\
\hline
\end{tabular}


solid particle ground calcium carbonate (GCC). In our previous work, we have reported the effect of different binders and binder doses on the porosity and wicking properties of the coating (Jutila et al. 2018, 2019; Koivunen et al. 2016).

\subsection{Inkjet printing}

\subsubsection{Hydrophobic patters}

While in previous studies we have employed hydrophobising inks with a variety of colourants (Jutila et al. 2018; Koivunen et al. 2016, 2019), in the present work a colourantfree hydrophobising ink was prepared to produce patterns that would have minimal effect on the coating background signal in colorimetric analysis. AKD in dry form is white, and, thus, when applied on the white pigment coatings, the printed pattern was only faintly visible to the naked eye, though still allowing for manual application of the glucose samples to the sample insertion zone. Alternatively, any other hydrophobising material that either matches the colour of the substrate when dry, or is transparent, could be employed for similar effect.

However, such poorly visible patterning also hinders ease of use of devices. A more practical design could involve printing a hydrophobic region immediately surrounding the detection zone with a colourant-free ink to minimise background signal; while, the rest of the hydrophobic pattern could be printed with a coloured ink.

\subsubsection{Enzymatic printing}

The average dry solids content of an inkjet deposited enzyme solution drop measured $2.09 \pm 0.02 \mathrm{ng}$; while, a manually pipetted drop measured on average $263 \pm 12 \mu \mathrm{g}$. The numbers of deposited drops, total dry solids and estimated enzyme volumes for the various printed patterns are listed in Table 5. The enzyme volume was estimated by comparing the total dry solids of each printed pattern to that of the manually deposited $1-\mu$ drop.

Previously, authors have reported using $0.2-1.5 \mu \mathrm{l}$ of enzymes in paper-based glucose assays (Cate et al. 2013;
Gabriel et al. 2016; 2017; Klasner et al. 2010; Martinez et al. 2008; Olkkonen et al. 2010). In these works, the enzymes have been spotted to the assays, probably using glass capillary tubes. Glucose reagents have also been inkjet-printed previously (Bihar et al. 2018; Wang et al., 2012; Wilson et al. 2015), but no estimates on the volume of applied enzymes have been given in these publications. We have shown that using inkjet-printing technology, that as little as nanolitre volumes of reagents can be applied successfully to the assays. In this work, we will show that these inkjetprinted nanolitre volumes of reagent solution are sufficient to produce functioning assays.

The employed enzyme solution was not in any form optimised for inkjet deposition, but simply employed to provide easy comparison with the manually applied enzyme tests. Based on our experience, we do not recommend the employed commercial enzyme capsules as a basis for inkjet ink development; while, conveniently containing both enzymes, they also contain a large amount of buffer salts of proprietary nature. When the ink dries on the substrate, these salts may affect the pore matrix structure and wicking properties. Furthermore, while the ink could be employed for the short duration printing tasks needed for this study, long-term jetting reliability is questionable, as instabilities in jetting causing stray droplets contacting the nozzle plate can lead to eventual build-up of dry material around the nozzle, with nozzle plate flooding possible when the meniscus contacts this material.

\subsection{Glucose experiments}

\subsubsection{Optimisation of the coating formulation}

In previous work, we have shown that MFC binders provide good wicking properties for the coatings making them suitable binders for microfluidic coating applications (Jutila et al. 2018, 2019; Koivunen et al. 2016). However, in addition to wicking, other properties, such as enzyme stability, are vital for fabrication of functional assays. PVOH does not provide as good wicking properties as MFC (Koivunen et al.
Table 5 Number of deposited drops, total dry solids and estimated enzyme volume applied per reaction zone

\begin{tabular}{lllc}
\hline Application method & Drops deposited & Total dry solids $(\mu \mathrm{g})$ & $\begin{array}{l}\text { Estimated } \\
\text { enzyme volume } \\
(\mathrm{nl})\end{array}$ \\
\hline Printed (tip $+0.0 \mathrm{~mm})$ & 1225 & $2.56 \pm 0.03$ & 10 \\
Printed (tip $+0.5 \mathrm{~mm})$ & 2536 & $5.30 \pm 0.06$ & 20 \\
Printed (tip $+1.0 \mathrm{~mm})$ & 3916 & $8.18 \pm 0.08$ & 31 \\
Printed (tip $+1.5 \mathrm{~mm})$ & 5296 & $11.1 \pm 0.11$ & 42 \\
Printed (tip $+2.0 \mathrm{~mm})$ & 6676 & $13.9 \pm 0.14$ & 53 \\
Manual pipetting & 1 & $263 \pm 12$ & 1000 \\
\hline
\end{tabular}



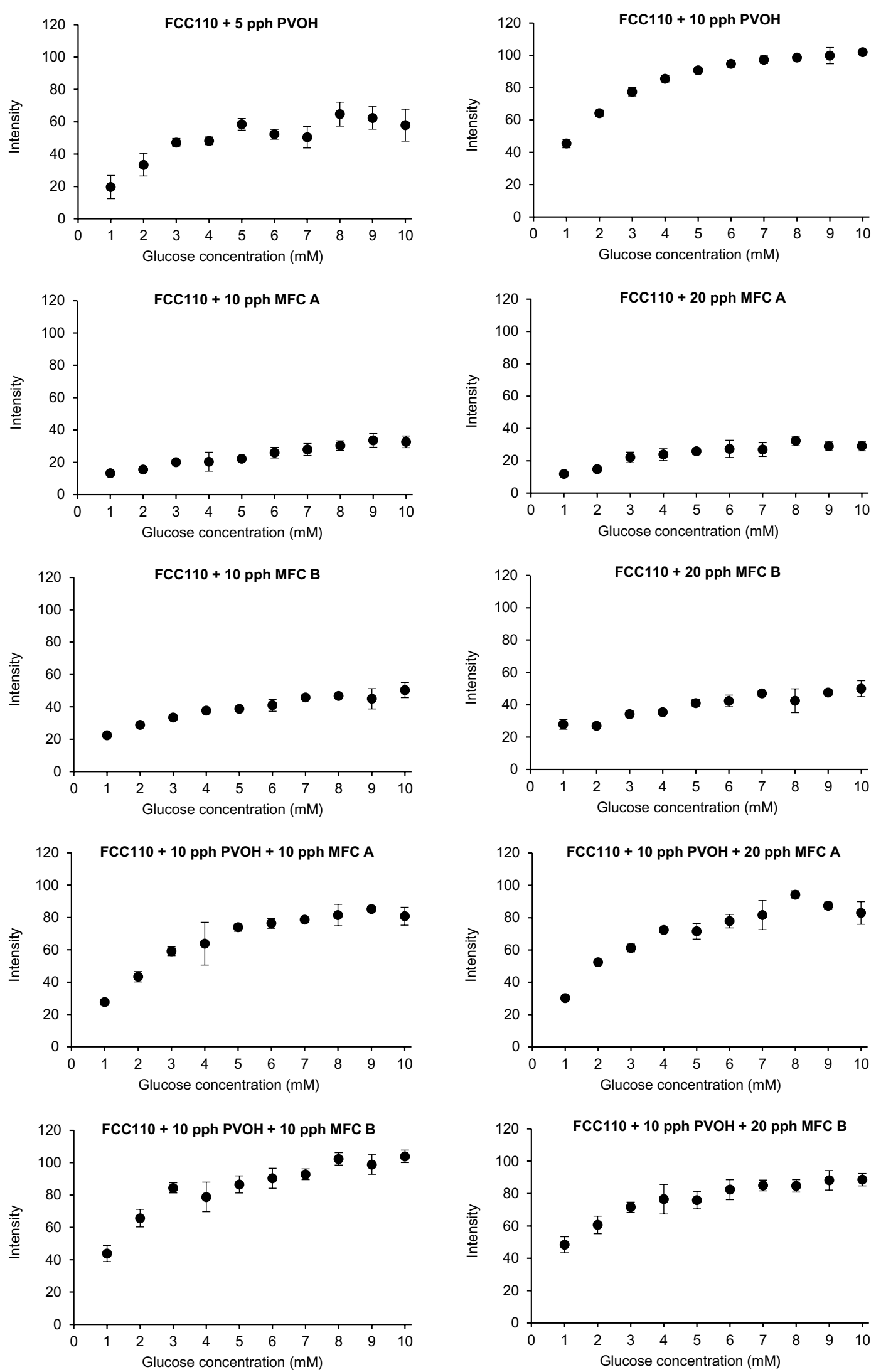

Fig. 4 Calibration curves of different coating formulations with the KI indicator $(n=3)$ 
2016), but it was chosen as one of the binders for this study because it is known to stabilise both HRP and GOx (Boyd and Yamazaki 1994; Boyd et al. 1996). Nanocellulose has also been used for enzyme immobilisation in glucose assays (Uddin et al. 2018; Esmaeili et al. 2015). Coatings consisting of both MFC and PVOH binders were prepared to maximise the wicking and stabilisation effects of both binders.

Figure 4 shows the calibration curves obtained using the potassium iodide (KI) indicator, which results in a brown colour change. The ring patterns leaked in the case of the FCC +5 pph PVOH coating, causing more variation between the repeats. $\mathrm{PVOH}$ increases the enzyme activity more than the microfibrillated cellulose MFC A or micro-nanofibrillated MFC B (Fig. 5). This can also be seen in Fig. 6, which shows the colour formation with MFC as a binder and the same coating with MFC plus additional PVOH as binders. MFC $B$ showed slightly higher enzyme activity than MFC A. This can probably be attributed to the nanofibrils present in MFC $\mathrm{B}$, which provide higher surface area and enhanced enzyme immobilisation capabilities than microfibrils alone. Higher $\mathrm{PVOH}$ dose was shown to have a stronger positive effect on enzyme activity than the increase in MFC dose. A small addition of MFC seemed to hinder enzyme activity slightly on the hybrid coatings containing both MFC and PVOH; however, due to the large error bars, it is difficult to make definite conclusions, especially in the case of MFC B. In the case of the formulation $\mathrm{FCC}+10 \mathrm{pph} \mathrm{PVOH}+10 \mathrm{pph} \mathrm{MFC} \mathrm{A}$, the intensity is somewhat lower than in the case of FCC $+10 \mathrm{pph}$ $\mathrm{PVOH}$. A higher MFC A dosage in turn results in a slightly higher intensity than what was achieved with FCC +10 pph

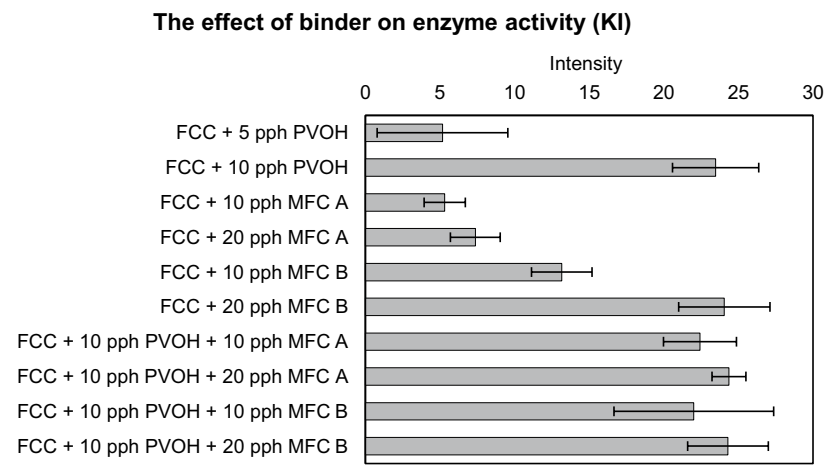

Fig. 5 The effect of binder on enzyme activity in the case of the KI indicator in the presence of 1-mM glucose after deduction of the background signal $(n=3)$

Fig. 6 The colour formation corresponding to glucose concentration in the KI ring experiments
PVOH. This is supported by the results which show that a higher intensity was achieved with FCC +20 pph MFC A than FCC +10 pph MFC A. The optimal coating formulation would still be a hybrid coating, though with lower MFC content, because PVOH does not provide as good wicking properties as MFC binders (Koivunen et al. 2016). Furthermore, using $\mathrm{PVOH}$ in the coating enables the use of lower enzyme volumes because of its positive effect on enzyme activity.

Figure 7, in turn, shows the calibration curves obtained the 4-AAP/DHBS indicator resulting in a pink colour change was used. More variation was observed between the repeats with the 4-AAP/DHBS indicator, because the differences in the intensity values between glucose concentrations are much smaller than the differences in the case of the KI indicator and, thus, the variation between the enzyme and glucose volumes, applied by hand, and the variations between coating homogeneity are more pronounced. Nevertheless, it is evident that the 4-AAP/DHBS indicator can be used to detect small glucose concentrations. The increase in the MFC binder dosage seemed to enhance the enzyme activity in most of the cases when the 4-AAP/DHBS indicator was used (Fig. 7), compared to the KI indicator, in which case a similar effect was not observed (Fig. 4). PVOH increased the intensity in the case of MFC A containing coatings. The addition of a PVOH did not result in a more intense colour formation in coatings containing MFC B binder (Fig. 8), as was shown also in the case of MFC B binder with the KI indicator (Fig. 6).

The results show that the choice of the indicator determines the sensitivity of the assay and that the sensitivity can also be tweaked using different binders and binder dosage levels. The required sensitivity, in turn, depends on the biological fluid used. A higher glucose range achieved with the KI indicator range is sufficient for glucose measurement from blood (Uddin et al. 2018). However, as taking a blood sample is an invasive method and using blood might be more problematic because of the different components of the blood, such as the blood cells, it would be more convenient to use a non-invasive sample, such as urine, tears or saliva. However, since the relevant glucose levels in urine (Sechi et al. 2013), saliva (Jia et al. 2018) and tear (Gabriel et al. 2017) samples are in the range of $0-1 \mathrm{mM}$, a more sensitive detection is required.

The assay stability is an important aspect of the functionality of the assay and the feasibility of the coated substrates. In addition to colour formation, therefore, the effect of the binder and binder dosage on the stability of the assays was examined using the $\mathrm{KI}$ indicator and a trehalose stabiliser. The KI indicator was used in these experiments, because it

\begin{tabular}{|c|c|c|c|c|c|c|c|c|c|c|}
\hline Glucose $(\mathrm{mM})$ & 0 & 1 & 2 & 3 & 4 & 5 & 6 & 7 & 8 & 9 \\
\hline $\mathrm{FCC}+10 \mathrm{pph}$ MFC B & & O & O & & C) & (2) & (2) & C & & 둥 \\
\hline $\mathrm{CC}+10 \mathrm{pph} \mathrm{PVOH}+10 \mathrm{pph} \mathrm{MFC} \mathrm{B}$ & & , & 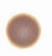 & & & $\mathrm{\rho}$ & & & & 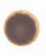 \\
\hline
\end{tabular}


Fig. 7 Calibration curves of different coating formulations with the 4-AAP/DHBS indicator $(n=3)$
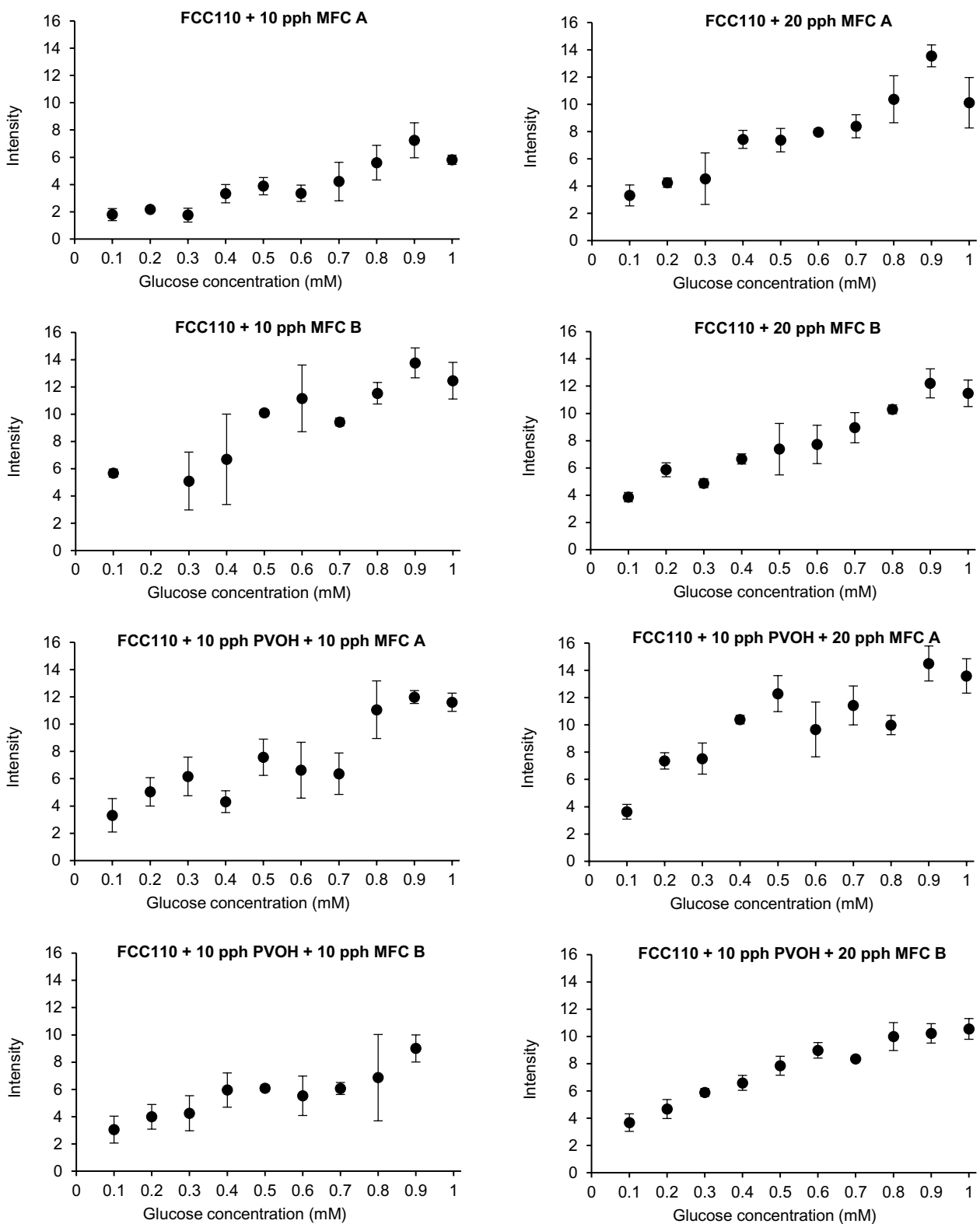

produces a stronger colour change than the 4-AAP/BHBD, and, therefore, the decreasing intensity and the differences between the different coating formulations could be observed better. Figure 9 shows the stability of the samples stored in the fridge $\left(6^{\circ} \mathrm{C}\right)$ over the period of four weeks. The stability of the enzymes on the reference paper substrate remained relatively stable over the four-week period with only a $6.6 \%$ decrease in stability. Enzymes on the coated substrates stayed active for two-three weeks. The best performing coating in terms of least decreased enzyme activity was FCC +10 pph MFC B with a $11.4 \%$ decrease; while, the coating with $10 \mathrm{pph} \mathrm{PVOH}$ showed the most significant decrease with a $58.4 \%$ drop in activity.
With a lower PVOH dosage level, the samples remained stable for four weeks, indicating that although the higher $\mathrm{PVOH}$ dose increased the enzyme activity initially more than the lower dose, excessive amounts of PVOH can have a negative impact on enzyme stability. This phenomenon was not further studied. However, a possible explanation could be related to adsorption and immobilisation of enzymes. Previous studies have also shown that GOx and HRP remain stable for longer when they are immobilised (Ozyilmaz et al. 2005; Temoçin and Yiğitoğlu 2009). Both PVOH (Soni and Jha 2015) and hydroxyapatite (Jesionowski et al. 2014) have been reported to enhance enzyme immobilisation by 
Fig. 8 The colour formation corresponding to glucose concentration in the 4-AAP/DHBS ring experiments

\begin{tabular}{r|lllllllllll} 
Glucose $(\mathrm{mM})$ & 0 & 0.1 & 0.2 & 0.3 & 0.4 & 0.5 & 0.6 & 0.7 & 0.8 & 0.9 & 1.0 \\
\hline FCC +20 pph MFC B & & & & & & & 0 & 0 & 0 & 0 & 0 \\
FCC +10 pph PVOH +20 pph MFC B & & & & & & & & & & & \\
\hline
\end{tabular}

adsorption. It is possible that the higher PVOH dose covers more of the hydroxyapatite of the coating and, thus, reduces the adsorption of the enzymes, but to confirm this would require further analysis. Furthermore, the stability of the assays could be potentially improved by switching to another $\mathrm{PVOH}$ with a lower molecular weight. It has been previously reported that a $\mathrm{PVOH}$ with a lower molecular weight $(\mathrm{Mw}$ $9000-10,000)$ and a lower degree of hydrolysis $(80 \%$ hydrolysed) provide the best stability for both HRP and GOx out of the various PVOHs tested (Boyd et al. 1996).

The type of FCC also seems to have an impact on assay stability. Our preliminary experiments (Jutila et al. 2017) also showed that the stability was greatly affected by the FCC pigment properties. Initially, an FCC with a lower hydroxyapatite content (53\%) was used (Jutila et al. 2018). Satisfactory detection curves were achieved, but the enzymes denaturated overnight. Therefore, a pigment with a higher hydroxyapatite content (85\%) was chosen for the experiments. Although calcium ions may enhance GOx activity (Kozhukharova et al. 1988) or at least should not inhibit the activity (Wu et al. 2017). Di Risio and Yan (2010) found that HRP binds onto calcium carbonate only weakly and believed this could explain why pigment-coated papers usually give poor analytical signals. However, unlike conventional calcium carbonate coatings for mass produced printing, our functionalised pigment coatings contain also varying degrees of hydroxyapatite conversion.

The results show that the coating formulation and, thus, the coating properties can be tweaked by changing the binder and the binder dosage to suit the needs of the application, and that specific optimisation may be required for different indicators. The results also show that the coatings display an acceptable performance over a period of time and, thus, offer a feasible alternative to cellulose-based paper substrates.

\subsubsection{Fully inkjet-printed glucose assays}

The fully inkjet-printed glucose assays were fabricated on two different coatings, one containing solely MFC B binder and the other containing both MFC B and PVOH as a hybrid binder system, and onto the reference chromatographic paper using the 4-AAP/DHBS indicator. The 4-AAP/DHBS indicator was chosen for the experiments, because it enables the detection of smaller glucose concentrations (Gabriel et al. 2016). As described earlier, the printed patterns here also consist of a circular sample insertion zone followed by a channel ending in a triangular tip (Fig. 3b). Preliminary experiments showed that a tip +1.5 -mm enzyme configuration, which corresponds to an estimated volume of $42 \mathrm{nl}$ of reagent solution provided the best results with regard to
Fig. 9 Stability of the hand pipetted enzymes stored in the fridge $\left(6^{\circ} \mathrm{C}\right)$ on different substrates. The stability was tested using a 5-mM glucose concentration

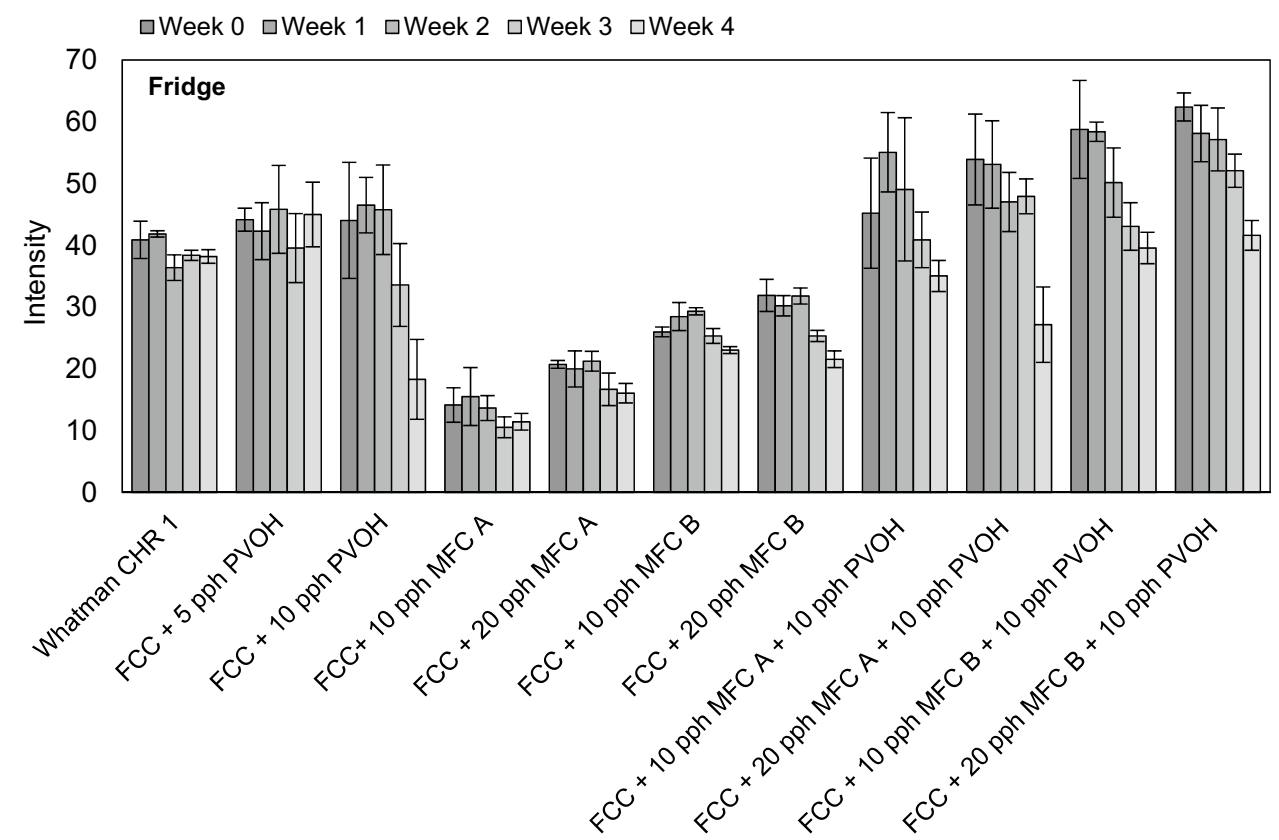


linearity, and, thus, the glucose experiments were performed with this enzyme volume.

The glucose sample volume was optimised to ensure that the glucose sample elutes to the tip of the assay. A volume of $0.5 \mu \mathrm{l}$ would have been sufficient to fully elute the glucose to the tip in the case of the coated substrates, but a larger $1-\mu l$ volume was seen to provide better reproducibility of the experiments. A 4- $\mu$ l volume was used in the case of the thicker reference paper to ensure elution to the tip, because the reference paper is much thicker and has a much larger pore and absorption volume than the coated samples, such that the 1- $\mu$ l volume would have not eluted to the tip of the pattern. This need for greater sample material is the major downside of traditional paper-only diagnostics, and is the very reason/driving force for developing finer pore size and lower pore volume coatings with strong wicking potential.

Figure 10 shows the calibration curves for the glucose assays. A good linearity was achieved between concentrations ranging from 0.1 to $0.6 \mathrm{mM}$ with the coated substrates. A limit of detection (LOD) of $0.04 \mathrm{mM}$ and limit of quantification (LOQ) of $0.12 \mathrm{mM}$ were achieved for the coating with MFC B binder (Fig. 10a). An LOD of $0.10 \mathrm{mM}$ and LOQ of $0.30 \mathrm{mM}$ for the hybrid binder coating with both MFC B and PVOH binders were also observed (Fig. 10b). However, it is evident that a lower enzyme dosage level could have been used in the experiments. The enzyme dose was optimised in preliminary experiments. However, the actual assay experiments were conducted with a fresh enzyme ink, which was proven to be more active than the ink used in the preliminary experiments. Two weeks later, the samples were printed with a lower enzyme dose $(31 \mathrm{nl})$ to see if a better linearity could be reached (Fig. 10c). Linearity was observed between 0.1 and $0.9 \mathrm{mM}$. However, since the enzyme ink had aged over the approximately two weeks compared with the original assays, the activity of the enzymes had already decreased significantly. A wider concentration range could have been achieved with further optimisation of the enzyme dose. Gabriel et al. (2016) achieved linearity between 0.1 and $1.0 \mathrm{mM}$ using the same indicator on a chitosan-modified filter paper. They achieved a slightly lower LOD $(0.023 \mathrm{mM})$ than could be achieved here with the coating adopting MFC B as binder. Nevertheless, these results show that the coated platforms offer a feasible alternative to commonly used filter paper.

Since a higher glucose volume $(4 \mu \mathrm{l}$ vs $1 \mu \mathrm{l})$ was used with the reference Whatman CHR1 substrate, the calibration curves of the coated substrates and the reference substrate cannot be directly compared. Nonetheless, linearity was achieved for the reference between 0.1- and 0.3-mM glucose (Fig. 10d) indicating that a much lower enzyme dosage would have been sufficient.

The PVOH containing coating shows a higher calibration slope compared to the plain MFC B containing coating, indicating that the $\mathrm{PVOH}$ increases the enzyme activity, as previously mentioned potentially through enhanced enzyme immobilisation. This can also be seen in Fig. 11 as a more intense pink colour development. PVOH did not seem to enhance enzyme activity in the optimisation tests with the circular ring patterns. It has been previously reported that
Fig. 10 Calibration curves for a MFC B containing coating with a higher enzyme dosage, $\mathbf{b}$ hybrid binder coating, c) MFC B containing coating with a lower enzyme dosage (printed two weeks after ink preparation), and $\mathbf{d}$ reference substrate $(n=15)$
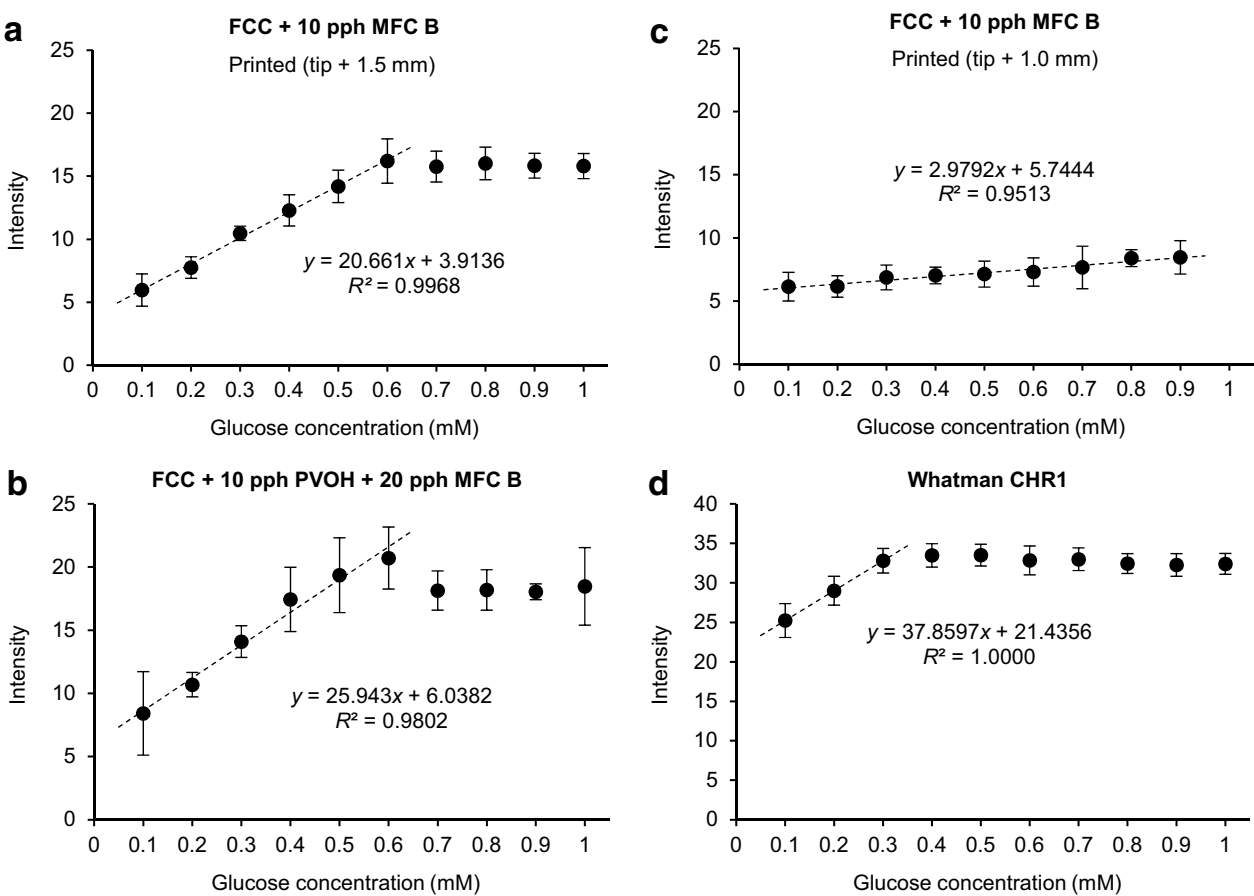
the activity of GOx and HRP is affected by both temperature and humidity (Ozyilmaz et al. 2005; Temoçin and Yiğitoğlu 2009; Lam et al. 2014). In this case, the experimental conditions are indeed different to those of the ring experiments, because glucose solution now elutes to the tip where the enzymes have been printed under normal laboratory conditions; whereas, the ring optimisation experiments were conducted in a climate-controlled environment, providing higher humidity levels. Humidity affects the coating structure, because the coating dries differently and absorbs moisture from its surroundings, and the $\mathrm{PVOH}$, being hygroscopic, may swell. Both of these factors may affect the wicking properties of the coating as well as elution of the colour front to the tip of the assay. These factors, therefore, only emphasise even more strongly to developers that coatings need to be tailored for a specific application. For example, a higher humidity may affect the wicking properties of the coating, depending on the sample system under test, due to "pre-wetting" the coating, including polymer matrix pre-swelling of $\mathrm{PVOH}$, though in this case colour change enhancement can be derived from this polymer matrix effect interacting directly with the sample.

The pink colour did not elute all the way to the tip of the coated samples, as can be seen in Fig. 11. This is probably related to the buffer salts present in the GOx/HRP capsule, which seem to travel with the eluent to the tip and block the pores at the very tip of the patterns. For this reason, the enzyme dosage was increased by printing a larger area of enzymes instead of printing multiple layers of enzyme ink to the triangular tip area.

Most of the colour front eluted closer to the tip area on the MFC B containing coating than on the hybrid binder coating containing both MFC and PVOH. This effect would not be as significant if the enzymes were printed solely at the tip. On the PVOH containing coating, the colour is probably arrested within the water-swollen PVOH matrix and thus part of it remained at the channel walls. Another possible explanation is that the transport of the colour front is significantly slowed down due to the region of poorly connected pores at the edge of the channel.

On the cellulose-based uncoated reference paper, the colour formation is more spread out than on the coated substrates. A fourfold increased volume of glucose containing solution was applied to assays fabricated on the reference paper leading to a more pronounced colour formation. With a lower glucose sample volume, the colour formation would have probably resembled that of the coated substrates, which show a coffee ring pattern. It has been shown that the enzymes remain uniformly distributed across the detection in paper-based glucose assays, while the $\mathrm{I}^{-}$ions are washed away to the sides of the patterns causing a coffee ring effect when the KI indicator is used (de Freitas et al. 2018). Chitosan (Gabriel et al. 2016) and gelatin (Cha et al. 2012; Zhu et al. 2014) have been used in some paper-based glucose assays to alter the surface of the paper and thus to obtain a more homogeneous colour formation. The effect of chitosan or gelatin was not explored in this study. However, an alternative design, in which the eluent would first pass the enzymes and then a printed cationic polyelectrolyte area could also be utilised to concentrate the colour on the coated substrates.

The error bars, which represent the standard deviation, could have been further minimised by determining the background signal of each measurement tip. The enzyme solution without indicators has a faint yellow colour, which seemed to intensify during storage. The enzyme ink containing 4-AAP/DHBS, in turn, turned slightly pink during storage. Therefore, the enzyme ink probably gives a faint intensity, which could have been eliminated by scanning the assays before and after printing the enzyme ink and determining background signal, which could be then deducted from the measurement intensity. However, in these experiments, the enzyme ink was pre-pared and used almost immediately and, therefore, the colour formation was minimised. Furthermore, scanning the samples after printing the enzyme ink might contaminate the samples causing premature colour

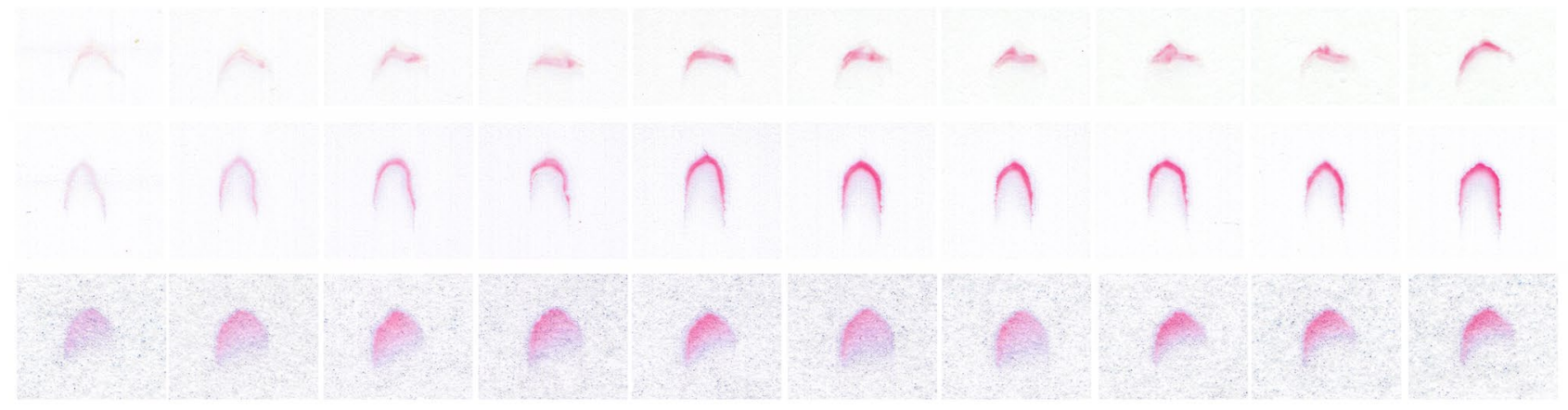

Fig. 11 Colour formation and elution to the tip area $\mathbf{a}$ FCC +10 pph MFC B, b FCC +10 pph PVOH +20 pph MFC B and $\mathbf{c}$ the reference Whatman CHR1 
formation as the samples are placed against the glass surface of the scanner. One solution could be the use of a camera instead of scanner, though the lighting conditions are much stable when using a flatbed scanner compared to a camera.

Figure 12 shows the stability of the fully inkjet-printed glucose assays fabricated on the two coated substrates and reference Whatman CHR1 paper tested with a glucose concentration of $0.6 \mathrm{mM}$. The coated samples were stored in three different conditions, room temperature, fridge $\left(6^{\circ} \mathrm{C}\right)$ and freezer $\left(-20^{\circ} \mathrm{C}\right)$. The reference paper samples were only stored in the fridge and freezer, because excess, unreacted AKD slowly spreads along fibres filling the hydrophilic assay area at room temperature, as also demonstrated in earlier studies (Seppänen et al. 2000). In case of coatings, no such spreading behaviour was observed, possibly due to the higher surface area of the coating, and the capillary pressure effect within pores trapping the AKD inside rather than allowing film flow. A significant drop in enzyme activity was seen during the first week with samples stored at room temperature and in the fridge, after which, the activity declined at a slower pace. The initial drop in activity can probably be attributed to a least two factors. Firstly, the enzymes ink components were allowed to dissolve into distilled water at room temperature for approximately $3 \mathrm{~h}$. According to the manufacturer, the dissolved enzymes should remain stable at $2-8{ }^{\circ} \mathrm{C}$ for up to a month and at least 6 months if stored at $-20^{\circ} \mathrm{C}$. Therefore, dissolving the enzyme ink components at room temperature probably had a negative effect on enzyme activity. Secondly, the inkjet-printing process has been reported to cause a decline in enzyme activity. The loss of activity can be related to printing conditions, such as actuation voltages (Cook et al. 2010), rapid compression experienced by the enzyme solution (Nishioka et al. 2004) or thermal degradation of the enzyme (Setti et al. 2004). In addition, high shear in the nozzle might be considered to damage the molecular structure of enzymes (Derby 2008). The printing conditions were not optimised to minimise enzyme activity loss in this study, and thus, longer stability could probably be achieved through optimisation of ink rheological properties and printing conditions, or using an enzyme stabiliser such as polyethylene glycol (Zhang et al. 2019).

The best assay stability was achieved when using samples stored frozen. Unlike with samples stored at room temperature and in the fridge, no significant drop in enzyme activity was observed during the first week. The enzymes remained stable for approximately four weeks on all three substrates. The reference substrate showed the lowest degradation in enzyme activity with only a $2.9 \%$ decrease, though the coated substrates also showed only moderate decrease in enzyme activity (4.3 and $4.4 \%$ ).

The results show that the highly porous pigment coatings are feasible substrates for microfluidic assay purposes with regard to detection sensitivity and stability when compared to a commonly used chromatography paper. The coated substrates also have some benefits compared to uncoated cellulose-based papers as observed during testing. For example, there is no risk of samples leaking from the assay or being contaminated from the underside, because of the PP film. Another benefit is the dimensional stability of the coating, which is not affected by the enzyme ink or the glucose solution, unlike the reference paper, which showed cockling on wetting and a wavy form after the assays had dried. Dimensional stability is essential for accurate image analysis, especially if a camera or a smartphone is used instead of a flatbed scanner under compression.
Fig. 12 Stability of the fully inkjet-printed glucose assay stored at room temperature, refrigerated $\left(6^{\circ} \mathrm{C}\right)$ and frozen $\left(-20^{\circ} \mathrm{C}\right)(n=15)$

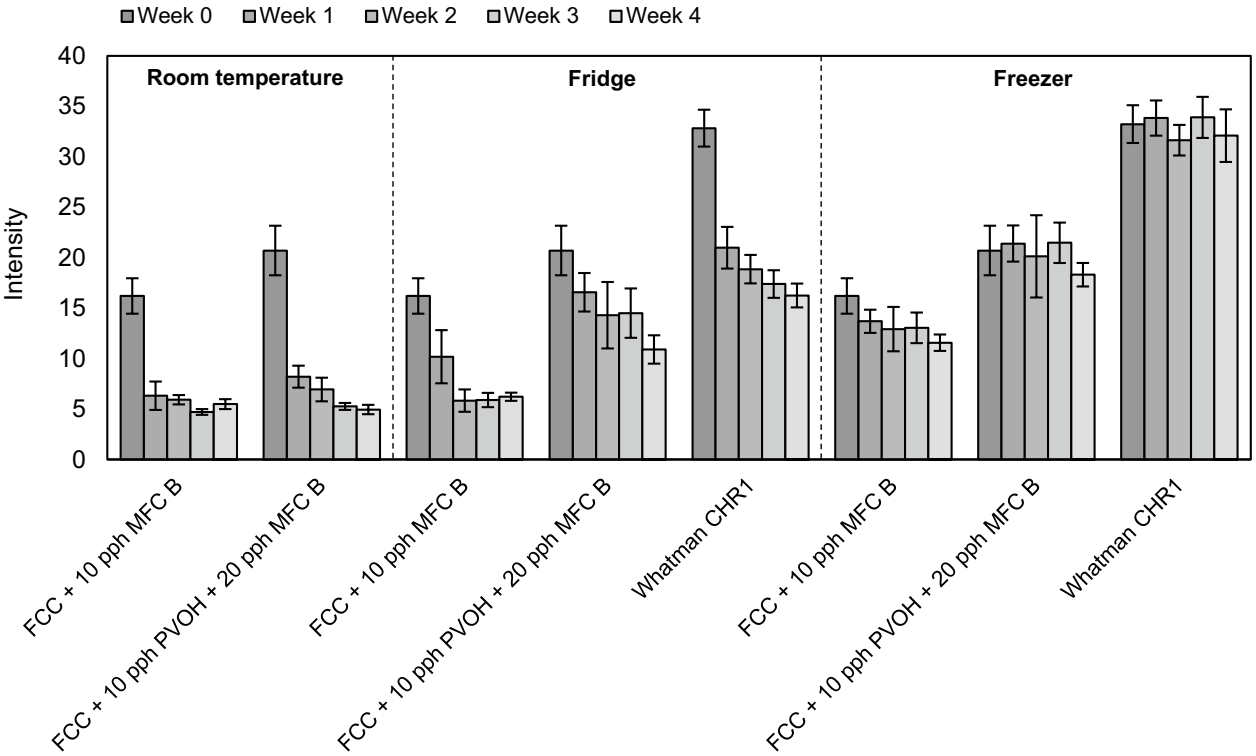


We have also demonstrated that the coated substrates enable the use of smaller enzyme and glucose volumes due to the thin lower volume coatings. Previously, researchers have reported spotting enzyme volumes as low as $0.2 \mu \mathrm{l}$ (Martine et al. 2008) and applying glucose solution volumes as low 5 ul (Klasner et al. 2010) in paper-based colorimetric glucose assays. GOx and HRP have also been printed with inkjet before, but exact ink volumes have not been reported in these publications (Martinez et al. 2008; Wilson et al. 2015; Bihar et al. 2018). We managed to bring the enzyme volume down to the nanolitre range with inkjet printing and the glucose volume to $1 \mu \mathrm{l}$, thanks to the thin coating layer. The ink and glucose solution volumes could be reduced even more by coating an even thinner coating layer. However, for practical reasons when used in the field, such as pipetting the glucose solution reliably manually, it is not advisable to fabricate too small assays. In a robotic analytical environment, however, the argument might be different.

\section{Conclusions}

In the present study, we developed a fully inkjet-printed glucose assay fabricated on thin highly porous pigment coating specially designed for microfluidic applications. We were able to fabricate a small glucose assay $\left(5.5 \times 13.5 \mathrm{~mm}^{2}\right)$ including the hydrophobic pattern), which utilises, to our knowledge, the smallest reported enzyme ink volume (42 nl) and a low glucose sample volume $(1 \mu \mathrm{l})$. Good linearity was achieved between glucose concentrations of 0.1 and $0.6 \mathrm{mM}$ on both developed coated substrates with an LOD of $0.04-0.10 \mathrm{mM}$ and LOQ of $0.12-0.30 \mathrm{mM}$. Furthermore, the assays remained relatively stable for four weeks when stored frozen $\left(-20^{\circ} \mathrm{C}\right)$. Manufacturing of such coated substrates could easily be upscaled and robust devices can be developed for point of care and in-field assay applications. With the advancement of robotic sampling in laboratory applications, this innovative coating design could allow for further miniaturisation.

Acknowledgements Open access funding provided by Aalto University. The project was funded by Omya International AG. Silvan Fischer (Omya International AG) is acknowledged for the SEM analysis, Melanie Kolb (Omya International AG) for determining pigment mineral content and Dan Gerard (Omya International AG) for the BET analysis. AKD sample was donated by Kemira. This work made use of Aalto University Bioeconomy Facilities.

Open Access This article is licensed under a Creative Commons Attribution 4.0 International License, which permits use, sharing, adaptation, distribution and reproduction in any medium or format, as long as you give appropriate credit to the original author(s) and the source, provide a link to the Creative Commons licence, and indicate if changes were made. The images or other third party material in this article are included in the article's Creative Commons licence, unless indicated otherwise in a credit line to the material. If material is not included in the article's Creative Commons licence and your intended use is not permitted by statutory regulation or exceeds the permitted use, you will need to obtain permission directly from the copyright holder. To view a copy of this licence, visit http://creativecommons.org/licenses/by/4.0/.

\section{References}

Abe K, Suzuki K, Citterio D (2008) Inkjet-printed microfluidic multianalyte chemical sensing paper. Anal Chem 80:6928-6934. https ://doi.org/10.1021/ac800604v

Abe K, Kotera K, Suzuki K, Citterio D (2010) Inkjet-printed paperfluidic immuno-chemical sensing device. Anal Bioanal Chem 398:885-893. https://doi.org/10.1007/s00216-010-4011-2

Abikshyeet P, Ramesh V, Oza N (2012) Glucose estimation in the salivary secretion of diabetes mellitus patients. Diabetes Metab Syndr Obes 5:149-154. https://doi.org/10.2147/DMSO.S32112

Adkins JA, Boehle K, Friend C, Chamberlain B, Bisha B, Henry CS (2017) Colorimetric and electrochemical bacteria detection using printed paper- and transparency-based analytic devices. Anal Chem 89:3613-3621. https://doi.org/10.1021/acs.analchem.6b050 09

Agrawal RP, Sharma N, Rathore MS, Gupta VB, Jain S, Agarwal V, Goyal S (2013) Non-invasive method for glucose level estimation by saliva. J Diabetes Metab 4:1-5. https://doi.org/10.4172/21556156.1000266

Baca JT, Finegold DV, Asher SA (2007) Tear glucose analysis for the non-invasive detection and monitoring of diabetes mellitus. Ocul Surf 5:280-293. https://doi.org/10.1016/S1542-0124(12)70094-0

Bihar E, Wustoni S, Pappa AM, Salama KN, Baran D, Inal S (2018) A fully inkjet-printed disposable glucose sensor on paper. npj Flex Electron 2:30. https://doi.org/10.1038/s41528-018-0044-y

Boyd S, Yamazaki H (1994) Use of polyvinyl alcohol as a stabilizer of peroxidase-antibody conjugate for enzyme immunoassay. Biotechnol Tech 8:123-128. https://doi.org/10.1007/BF00152852

Boyd S, Letcher K, Yamazaki H (1996) Stabilization effect of polyvinyl alcohol on horseredish peroxidase, glucose oxidase, $\beta$-galactosidase and alkaline phosphatase. Biotechnol Tech 10:693-698. https://doi.org/10.1007/BF00168482

Busa LSA, Mohammadi S, Maeki M, Ishida A, Tani H, Tokeshi M (2016) Advances in microfluidic paper-based analytical devices for food and water analysis. Micromachines 7:86. https://doi. org/10.3390/mi7050086

Cate DM, Dungchai W, Cunningman JC, Volckens J, Henry CS (2013) Simple, distance-based measurement for paper analytical devices. Lab Chip 13:2397-2404. https://doi.org/10.1039/C3LC50072A

Cate DM, Adkins JA, Mettakoonpitak J, Henry CS (2015) Recent developments in paper-based microfluidic devices. Anal Chem 87:1-9. https://doi.org/10.1021/ac503968p

Cha R, Wang D, He Z, Ni Y (2012) Development of cellulose paper testing strips for quick measurement of glucose using chromogen agent. Carbohyd Polym 88:1414-1419. https://doi.org/10.1016/j. carbpol.2012.02.028

Chun HJ, Park YM, Han YD, Jang YH, Yoon HC (2014) Paper-based glucose biosensing system utilizing a smartphone as a signal reader. BioChip J 8:218-226. https://doi.org/10.1007/s1320 6-014-8308-7

Cinti S, Proietti E, Casotto F, Moscone D, Arduini F (2018) Paperbased strips for the electrochemical detection of single and double stranded DNA. Anal Chem 90:13680-13686. https://doi. org/10.1021/acs.analchem.8b04052 
Cook CC, Wang T, Derby B (2010) Inkjet delivery of glucose oxidase. Chem Comm 46:5452-5454. https://doi.org/10.1039/ $\mathrm{c} 0 \mathrm{cc} 00567 \mathrm{c}$

Costa MN, Veigas B, Jacob JM, Santos DS, Gomes J, Baptista PV, Martins R, Inácio J, Fortunato E (2014) A low cost, safe, disposable, rapid and self-sustainable paper-based platform for diagnostic testing: lab-on-paper. Nanotechnology 25:094006. https://doi. org/10.1088/0957-4484/25/9/094006

de Freitas SV, de Souza FR, Neto JCR, Vasconcelos GA, Abdelnur PV, Vaz BG, Henry CS, Coltro WKT (2018) Uncovering the formation of color gradients for glucose colorimetric assays on microfluidic paper-based analytical devices by mass spectrometry imaging. Anal Chem 90:11949-11954. https://doi.org/10.1021/ acs.analchem. $8 \mathrm{~b} 02384$

Derby B (2008) Bioprinting: inkjet printing proteins and hybrid cellcontaining materials and structures. J Mater Chem 18:5717-5721. https://doi.org/10.1039/B807560C

Di Risio S, Yan N (2010) Adsorption and inactivation behavior of horseradish peroxidase on various substrates. Colloids Surf B 79:397-402. https://doi.org/10.1016/j.jcis.2009.07.005

Dungchai W, Chailapakul O, Henry CS (2010) Use of multiple colorimetric indicators for paper-based microfluidic devices. Anal Chim Acta 674:227-233. https://doi.org/10.1016/j.aca.2010.06.019

Esmaeili C, Abdi MM, Mathew AP, Jonoobi M, Oksman K, Rezayi M (2015) Synergy effect of nanocrystalline cellulose for the biosensing detection of glucose. Sensors 15:24681-24697. https://doi. org/10.3390/s151024681

Evans E, Gabriel EFM, Coltro WKT, Garcia CD (2014) Rational selection of substrates to improve color intensity and uniformity on microfluidic paper-based analytical devices. Analyst 139:21272132. https://doi.org/10.1039/C4AN00230J

HUSLAB (2019) Glukoosi, yövirtsasta (aamuvirtsasta). HUSLAB. https://huslab.fi/ohjekirja/3411.html. Accessed 2 Feb 2020

Gabriel EFM, Garcia PT, Cardoso TMG, Lopes FM, Martins FT, Coltro WKT (2016) Highly sensitive colorimetric detection of glucose and uric acid in biological fluids using chitosan-modified paper microfluidic devices. Analyst 141:4749-4756. https://doi. org/10.1039/C6AN00430J

Gabriel EFM, Garcia PT, Lopes FM, Coltro WKT (2017) Paper-based colorimetric biosensor for tear glucose measurements. Micromachines 8:104. https://doi.org/10.3390/mi8040104

Ghaderinezhad F, Amin R, Temirel M, Yenilmez B, Wentworth A, Tasoglu S (2017) High-throughput rapid-prototyping of lowcost paper-based microfluidics. Sci Rep 7:3553. https://doi. org/10.1038/s41598-017-02931-6

Jesionowski T, Zdarta J, Krajewska B (2014) Enzyme immobilization by adsorption: a review. Adsorption 20:801-821. https://doi. org/10.1007/s10450-014-9623-y

Jia Y, Sun H, Li X, Sun D, Hu T, Xiang N, Ni Z (2018) Paper-based graphene oxide biosensor coupled with smartphone for the quantification of glucose in oral fluid. Biomed Microdevices 20:89. https://doi.org/10.1007/s10544-018-0332-2

Jutila E, Koivunen R, Bollström R, Gane P (2017) Inkjet-fabricated coated reaction platform for colorimetric glucose detection. Adv Print Media Technol 44:63-70

Jutila E, Koivunen R, Kiiski I, Bollström R, Sikanen T, Gane P (2018) Microfluidic lateral flow cytochrome p450 assay on a novel printed functionalized calcium carbonate-based platform for rapid screening of human xenobiotic metabolism. Adv Funct Mater 28:1802793. https://doi.org/10.1002/adfm.201802793

Jutila E, Koivunen R, Bollström R, Gane P (2019) Wicking and chromatographic properties of highly porous functionalised calcium carbonate coatings custom-designed for microfluidic devices. J Micromech Microeng 29:055004. https://doi.org/10.1088/13616439/ab0941
Klasner SA, Price AK, Hoeman KW, Wilson RS, Bell KJ, Culbertson CT (2010) Paper-based microfluidic devices for analysis of clinically relevant analytes present in urine and saliva. Anal Bioanal Chem 397:1821-1829. https://doi.org/10.1007/s0021 6-010-3718-4

Koivunen R, Jutila E, Bollström R, Gane P (2016) Hydrophobic patterning of functional porous pigment coatings by inkjet printing. Microfluid Nanofluid 20:83. https://doi.org/10.1007/s1040 4-016-1747-9

Koivunen R, Jutila E, Bollström R, Gane P (2017) Inkjet printed polyelectrolyte patterns for analyte separation on inherently porous microfluidic analytical designs. Colloid Surf A 522:218-232. https://doi.org/10.1016/j.colsurfa.2017.03.001

Koivunen R, Jutila E, Bollström R, Gane P (2019) Investigating chromatographic interactions in porous pigment coatings between inkjettable polyelectrolytes and model colorant solutions. Colloid Surf A 579:123676. https://doi.org/10.1016/j.colsurfa.2019.12367 6

Kong T, You JB, Zhang B, Nguyen B, Tarlan F, Jarvi K, Sinton D (2019) Accessory-free quantitative smartphone imaging of colorimetric paper-based assays. Lab Chip 19:1991-1999. https:// doi.org/10.1039/C9LC00165D

Kozhukharova A, Kirova N, Popova Y, Batsalova K, Kunchev K (1988) Properties of glucose oxidase immoblized in gel of polyvinylalcohol. Biotechnol Bioeng 32:245-248. https://doi.org/10.1002/ bit.260320216

Lam M, Louie RF, Curtis CM, Ferguson WJ, Vy JH, Truong A-H, Sumner SL, Kost GJ (2014) Short-term thermal-humidity shock affects point-of-care glucose testing implications for health professionals and patients. J Diabetes Sci Technol 8:83-88. https://doi. org/10.1177/1932296813514325

Lamas-Ardisana PJ, Martínez-Paredes L, Añorga L, Grande HJ (2018) Glucose biosensor based on disposable electrochemical paperbased transducers fully fabricated by screen-printing. Biosens Bioelectron 109:8-12. https://doi.org/10.1016/j.bios.2018.02.061

Limpan N, Prodpran T, Benjakul S, Prasarpran S (2012) Influences of degree of hydrolysis and molecular weight of poly(vinyl alcohol) (PVA) on properties of fish myofibrillar protein/PVA blend films. Food Hydrocoll 29:226-233. https://doi.org/10.1016/j. foodhyd.2012.03.007

Liu M-M, Lian X, Liu H, Guo Z-Z, Huang H-H, Lei Y, Peng H-P, Chen W, Lin X-L, Liu A-L, Xia X-H (2019) A colorimetric assay for sensitive detection of hydrogen peroxide and glucose in microfluidic paper-based analytical devices integrated with starch-iodidegelatin system. Talanta 200:511-517. https://doi.org/10.1016/j. talanta.2019.03.089

Lu Y, Shi W, Qin J, Lin B (2010) Fabrication and characterization of paper-based microfluidics prepared in nitrocellulose membrane by wax printing. Anal Chem 82:329-335. https://doi.org/10.1021/ ac9020193

Määttänen A, Fors D, Wang S, Valtakari D, Ihalainen P, Peltonen J (2011) Paper-based planar reaction arrays for printed diagnostics. Sens Actuat B 160:1404-1412. https://doi.org/10.1016/j. snb.2011.09.086

Manbohi A, Ahmadi SH (2019) Sensitive and selective detection of dopamine using electrochemical microfluidic paper-based analytical nanosensor. Sens Biosens Res 23:100270. https://doi. org/10.1016/j.sbsr.2019.100270

Mani NK, Prabhu A, Biswas SK, Chakraborty S (2019) Fabricating paper based devices using correction pens. Sci Rep 9:1752. https ://doi.org/10.1038/s41598-018-38308-

Martinez AW, Phillips ST, Butte MJ, Whitesides GM (2007) Patterned paper as a platform for inexpensive, low-volume, portable bioassays. Angew Chem 46:1318-1320. https://doi.org/10.1002/ anie. 200603817 
Martinez AW, Phillips ST, Carrilho E, Thomas SW III, Sindi H, Whitesides GM (2008) Simple telemedicine for developing regions: camera phones and paper-based microfluidic devices for realtime, off-site diagnosis. Anal Chem 80:3699-3707. https://doi. org/10.1021/ac800112r

Meredith NA, Quinn C, Cate DM, Reilly TM III, Volckens J, Henry CS (2016) Paper-based analytical devices for environmental analysis. Analyst 141:1874-1887. https://doi.org/10.1039/C5AN02572A

Mettakoonpitak J, Boehle K, Nantaphol S, Teengam P, Adkins JA, Srisa-Art M, Henry CS (2016) Electrochemistry on paper-based analytical devices: a review. Electroanal 28:1420-1436. https:// doi.org/10.1002/elan.201501143

Nishioka GM, Markey AA, Holloway CK (2004) Protein damage in drop-on-demand printers. J Am Chem Soc 126:16320-16321. https://doi.org/10.1021/ja044539z

Olkkonen J, Lehtinen K, Erho T (2010) Flexographically printed fluidic structures in paper. Anal Chem 82:10246-10250. https://doi. org/10.1021/ac1027066

Ozyilmaz G, Tukel SS, Alptekin O (2005) Activity and storage stability of immobilized glucose oxidase onto magnesium silicate. J Mol Catal 35:154-160. https://doi.org/10.1016/j.molcatb.2005.07.001

Ridgway CJ, Gane PAC, Schoelkopf J (2004) Modified calcium carbonate coatings with rapid absorption and extensive liquid uptake capacity. Colloid Surf A 236:91-102. https://doi.org/10.1016/j. colsurfa.2003.12.030

Ridgway CJ, Gane PAC, Schoelkopf J (2006) Achieving rapid absorption and extensive liquid uptake capacity in porous structures by decoupling capillarity and permeability: nanoporous modified calcium carbonate. Transp Porous Med 63:239-259. https://doi. org/10.1007/s11242-005-5391-1

Santana-Jiménez LA, Márquez-Lucero A, Osuna V, Estrada-Moreno I, Dominguez RB (2018) Naked-eye detection of glucose in saliva with bienzymatic paper-based sensor. Sensors 18:1071. https:// doi.org/10.3390/s18041071

Schenker M, Schoelkopf J, Mangin P, Gane P (2016) Rheological investigation of complex micro and nanofibrillated cellulose (MNFC) suspensions: discussion of flow curves and gel stability. Tappi J 5:405-416. https://doi.org/10.32964/TJ15.6.405

Schenker M, Schoelkopf J, Mangin P, Gane P (2017) Influence of shear rheometer measurement systems on the rheological properties of microfibrillated cellulose (MFC) suspensions. Cellulose 25:961976. https://doi.org/10.1007/s10570-017-1642-x

Sechi D, Greer B, Johnson J, Hashemi N (2013) Three-dimensional paper-based microfluidic device for assays of protein and glucose in urine. Anal Chem 85:10733-10737. https://doi.org/10.1021/ ac4014868

Seppänen R, Tiberg F, Valignat M-P (2000) Mechanism of internal sizing by alkyl ketene dimers (AKD): The role of the spreading monolayer precursor and autophobicity. Nord Pulp Pap Res J 15:452-458. https://doi.org/10.3183/npprj-2000-15-05-p452-458

Setti L, Piana C, Bonazzi S, Ballarin B, Francaro D, Fraleoni-Morgera A, Giuliani S (2004) Thermal inkjet technology for the microdeposition of biological molecules as a viable route for the realization of biosensors. Anal Lett 37:1559-1570. https://doi. org/10.1081/AL-120037587

Songok J, Toivakka M (2016) Controlling capillary-driven surface flow on a paper-based microfluidic channel. Microfluid Nanofluid 20:63. https://doi.org/10.1007/s10404-016-1726-1

Soni A, Jha SK (2015) A paper strip based non-invasive glucose biosensor for salivary analysis. Biosens Bioelectron 67:736-768. https://doi.org/10.1016/j.bios.2014.09.042
Soni A, Jha SK (2017) Smartphone based non-invasive salivary glucose biosensor. Anal Chim Acta 996:54-63. https://doi.org/10.1016/j. aca.2017.10.003

Syedmorai L, Gomez FA (2017) Paper-based point-of-care testing in disease diagnostics. Bioanalysis 9:841-843. https://doi. org/10.4155/bio-2017-0080

Temoçin Z, Yiğitoğlu M (2009) Studies on the activity and stability of immobilized horseradish peroxidase on poly(ethylene terephthalate) grafted acrylamide fiber. Bioprocess Biosyst Eng 32:467474. https://doi.org/10.1007/s00449-008-0266-9

Thom NK, Lewis GG, Yeung K, Phillips ST (2014) Quantitative fluorescence assays using a self-powered paper-based microfluidic device and a camera-equipped cellular phone. RSC Adv 4:13341340. https://doi.org/10.1039/C3RA44717K

Tiongco R-E, Bituin A, Arceo E, Rivera N, Singian E (2018) Salivary glucose as a non-invasive biomarker of type 2 diabetes mellitus. J Clin Exp Dent 10:e902-e907. https://doi.org/10.4317/jced.55009

Uddin KMA, Jokinen V, Jahangiri F, Franssila S, Rojas OJ, Tuukkanen S (2018) Disposable microfluidic sensor based on nanocellulose for glucose detection. Glob Chall 3:1800079. https://doi. org/10.1002/gch2.201800079

Wang T, Cook CC, Serban S, Ali T, Drago G, Derby B (2012) Fabrication of glucose biosensors by inkjet printing. arXiv:1207.1190.

Weng X, Neethirajan (2017) Paper-based microfluidic aptasensor for food safety. J Food Saf 38:e12412. https://doi.org/10.1111/ jfs. 12412

Wilson KG, Ovington P, Dean D (2015) A low-cost inkjet-printed glucose test strip system for resource-poor settings. J Diabetes Sci Technol 9:1275-1281. https://doi.org/10.1177/1932296815 589755

World Health Organisation (2019) Classification of diabetes mellitus. World Health Organisation. https://apps.who.int/iris/rest/bitst reams/1233344/retrieve. Accessed 2 Feb 2020

Wu Y-h, Chu L, Liu W, Jiang L, Chen X-y, Wang Y-h, Zhao Y-1 (2017) The screening of metal ion inhibitors for glucose oxidase based on the peroxidase-like activity of nano-Fe3O4. RSC Adv 7:47309. https://doi.org/10.1039/C7RA07081K

Yin W, Qin W, Goa Y (2018) Urine glucose levels are disordered before blood glucose level increase was observed in Zucker diabetic fatty rats. Sci China Life Sci 61:844-848. https://doi.org/10.1007/s1142 7-017-9134-6

Zhang H, Smith E, Zhang W, Zhou A (2019) Inkjet printed microfluidic paper-based analytical device $(\mu \mathrm{PAD})$ for glucose colorimetric detection in artificial urine. Biomed Microdevices 21:48. https:// doi.org/10.1007/s10544-019-0388-7

Zhong ZW, Wang ZP, Huang GXD (2012) Investigation of wax and paper materials for the fabrication of paper-based microfluidic devices. Microsyst Technol 18:649-659. https://doi.org/10.1007/ s00542-012-1469-1

Zhu W-J, Feng D-Q, Chen M, Chen Z-D, Zhu R, Fang H-L, Wang W (2014) Bienzyme colorimetric detection of glucose with self-calibration based on tree-shaped paper strip. Sens Actuat B 190:414-418. https://doi.org/10.1016/j.snb.2013.09.007

Publisher's Note Springer Nature remains neutral with regard to jurisdictional claims in published maps and institutional affiliations. 